NASA Technical Memorandum 89873

AIAA-87-1766

\title{
Numerical Modeling of On-Orbit Propellant Motion Resulting From an Impulsive Acceleration
}

John C. Aydelott

Lewis Research Center

Cleveland, Ohio

Raymond C. Mjolsness and Martin D. Torrey

Los Alamos National Laboratory

Los Alamos, New Mexico

and

John I. Hochstein

Washington University

St. Louis, Missouri

(NASA-TH-89873) ACEEGICAL ACEEIIAG OF CA-OBEIT ERCELIIAET MCIICN ELCULIIUG FGOH AN

I HEOLSIVE ACCELERAITCA (NASA) 24 p Avail:

NIIS EC $\mathrm{OO2} / \mathrm{AF} \quad 101$ CSCL $22 \mathrm{C}$

G3 Onclas

0076849

Prepared for the

23rd Joint Propulsion Conference

cosponsored by the AIAA, SAE, ASME, and ASEE

San Diego, California, June 29-July 2, 1987 
John C. Aydelott

National Aeronautics and Space Administration

Lewis Research Center

Cleveland, Ohio 44135

Raymond C. Mjolsness and Martin D. Torrey

Los Alamos National Laboratory

Los Alamos, New Mexico 87545

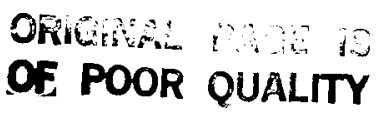

and

John I. Hochstein

Washington University

St. Louis, Missouri 63130

\section{Abstract}

In-space docking and separation maneuvers of spacecraft that have large fluid mass fractions may cause undesirable spacecraft motion in response to the impulsive-acceleration-induced fluid motion. An example of this potential lowgravity fluid management problem arose during the development of the shuttle/Centaur vehicle. Experimentally verified numerical modeling techniques were developed to establish the propellant dynamics, and subsequent vehicle motion, associated with the separation of the Centaur vehicle from the shuttle orbiter cargo bay. Although the shuttle/Centaur development activity has been suspended, the numerical modeling techniques are available to predict on-orbit liquid motion resulting from impulsive accelerations for other missions and spacecraft.

\section{Introduction}

The NASA Lewis Research Center has a long history of providing technology for the design and operation of fluid systems in the reducedgravity environment of space. 1 This technology program has provided support for the Centaur vehicle development effort in the form of both analytical and experimental studies. Recently the Centaur was being modified to make it compatible with the shuttle for launch of the Galileo and Ulysses spacecraft. During this Centaur redesign effort concern arose over the dynamics associated with the separation of the Centaur vehicle from the shuttle cargo bay.

Before separation from the shuttle orbiter the Centaur vehicle was to be rotated out of the cargo bay by a deployment mechanism attached to the Centaur integrated support structure (CISS). The two vehicles were then to be separated by release of several CISS-mounted springs positioned circumferentially around the aft Centaur structure. These springs would impart a separation force to the Centaur vehicle along its central axis that would yield a differential velocity between the orbiter and the Centaur of approximately $1 \mathrm{ft} / \mathrm{sec}$. However, because of predeployment shuttle maneuvers and atmospheric drag the propellant in the Centaur vehicle was not likely to be positioned symmetrically with respect to the vehicle axis. Consequently the resulting spring force at separation would probably not have acted through the center of gravity of the Centaur vehicle, and rotational motion of the Centaur relative to the orbiter could have occurred. A safety concern thus arose over whether this possible Centaur rotation would be severe enough to cause impact between the Centaur and the CISS or the shuttle orbiter.

This paper presents the results obtained from an experimental program conducted in the Lewis Zero-Gravity Facility to study fluid motion resulting from an impulsive acceleration. The data were used to verify numerical modeling techniques that were then employed to assess the importance of the Centaur separation dynamics concern. The recently released NASA-VOF3D computer code, developed at the Los Alamos National Laboratory, was employed to perform the numerical modeling. This computer code provides unique treatment of low-gravity, surface-tension-dominated fluid dynamic phenomena so that the propellant motion before and after the application of the accelerating force can be numerically modeled. The computer code predicts not only the propellant motion but also the resulting pressure field in the Centaur propellant tanks. These computer-generated tank pressure fields can then be employed in a vehicle dynamics analysis to establish the Centaur motion during separation from the shuttle cargo bay. Because of the relative weights of the liquid hydrogen and oxygen propellants the influence of the hydrogen propellant motion on the resulting Centaur vehicle motion would have been minimal. Consequently the experimental and analytical efforts focused on predicting the liquid oxygen propellant motion.

\section{Experimental Program}

The major goal of the experimental program was to verify the capability of a numerical analysis to predict the behavior of a liquid subjected to an impulsive acceleration. An earlier in-house experimental program ${ }^{2}$ established possible zerogravity locations of the oxygen tank vapor bubble before the Centaur separation. The work reported on herein examined the subsequent liquid-vapor bubble motion resulting from an impulse similar, but not scaled, to the separation maneuver. Scaling was not attempted because the shuttle/Centaur program was faced with the challenge of launching the Galileo and Ulysses spacecraft during the second quarter of 1986. Consequently the program used existing hardware so that the experimental data could be obtained in time to support the projected launch date. 
The Zero-Gravity Facility (Fig. 1) consists of a concrete-lined 8.7-m-diameter shaft that extends $155 \mathrm{~m}$ below ground level. A steel vacuum chamber, $6.1 \mathrm{~m}$ in diameter and $142 \mathrm{~m} \mathrm{high,} \mathrm{is} \mathrm{con-}$ tained within the concrete shaft. By using the Lewis wind tunnel exhaust system in series with vacuum pumps located in the facility, the pressure in the vacuum chamber is reduced to $13.3 \mathrm{~N} / \mathrm{m}^{2}$ $\left(1.3 \times 10^{-4} \mathrm{~atm}\right)$. The residual air in the drop chamber after pumpdown does produce a very low drag on the experimental drop package, but this force results in an equivalent acceleration acting on the package that is estimated to be no greater than $10^{-5} \mathrm{~g}$, thus providing an essentially zerogravity environment. Dropping the package from the top of the chamber results in approximately $5 \mathrm{sec}$ of free-fall time. The package is suspended from the top of the vacuum chamber by a support shaft (connected to the cylindrical section of the package) on a hinged-plate assembly. Once chamber pumpdown is completed, the package is released by pneumatically shearing a bolt that holds the hinged plate in a closed position. Following the free-fall period the package is decelerated at the bottom of the chamber in a cart filled with small pellets of expanded polystyrene. After the drop the vacuum chamber is vented to the atmosphere and the drop package is returned to ground level.

\section{Experimental Drop Package}

The experimental drop package (Fig. 2) consisted of a cylindrical section housing the experimental apparatus and the electrical systems. A closer view of the experimental apparatus is shown in Fig. 3 and a schematic diagram in Fig. 4. Located below the test tray were 28-V battery packs that supplied and regulated direct current to the experiment.

The hardware mounted on the test tray (Fig. 2) included a high-speed motion picture camera, a digital clock, a lighting system, and the test tank. The test tank was mounted on a cradle fastened to a linear bearing slide assembly (Fig. 3). During the drop a lateral acceleration was applied to the test tank by an air cylinder system (Fig. 4). The air cylinder consisted of a piston head (inside the cylinder walls) and a piston shaft, which extended beyond the end of the cylinder. The piston shaft was designed to push against the test tank frame, which was held in place with a retaining pin. During the drop the retaining pin was retracted by a solenoid. This allowed the prepressurized air cylinder to impart an acceleration to the test tank. The time during which the force was applied to the tank was controlled by adjusting the length of the piston stroke. Once the piston reached the end of its stroke and no longer was in contact with the tank, the tank slid on the linear bearing at a constant velocity.

The length of the linear bearing, and therefore the distance that the tank could travel after being accelerated, was dictated by the experimental drop package dimensions and the need to view the entire carriage displacement. Although it would have been desirable, space was not available on the slide assembly to mount the camera. However, through the use of a wide-angle lens it was possible to view approximate?y $27 \mathrm{~cm}$ of container motion with the rigidly attached camera. The fact that the camera was not mounted on the slide assembly made it nearly impossible to precisely measure the fluid motion because of both refraction and parallax effects (discussed in detail in the following section, "Data Analysis"). The tank displacement was measured by tracking the motion of pointers attached to the test tank, against a scale accurate to $1 \mathrm{~mm}(\mathrm{Fig} .3)$. The scale was mounted above the container in the same plane as the tank centerline and in the camera's field of view.

\section{Test Tank and Liquids}

The test tank was an oblate spheroid (ellipsoid) formed from a clear acrylic plastic, with semimajor and semiminor axes of 2.00 and $1.47 \mathrm{~cm}$, respectively (Figs. 5 and 6 ). This tank geometry was chosen for the test program because of its similarity with the liquid-oxygen tank used on the Centaur vehicle. The tank was fabricated in two halves and bolted together with an 0-ring seal as illustrated in Fig. 6 .

The liquids used in the zero-gravity tests were ethanol and FC-43. Both liquids exhibited a near $0^{\circ}$ contract angle on the spheroidal tank walls. The near $0^{\circ}$ contact angle characteristic is identical with that of liquid oxygen on the Centaur liquid-oxygen-tank surface. Other key properties of the test 1 iquids and liquid oxygen (i.e., surface tension, density, and viscosity) are presented in Table I.

It would have desirable to select fluids for the experimental program that had viscosity close to that of liquid oxygen. However, the results presented in Ref. 2 indicate that low-viscosity fluids take so long to form the zero-gravity liquid-vapor interface configuration that the 5-sec drop time would not be sufficient to allow the subsequent acceleration of the test tank. Consequently test fluids with a significant variation in viscosity were selected to determine whether the numerical analysis correctly accounted for viscosity effects.

\section{Test Setup and Procedure}

Before each series of tests the test tank was cleaned ultrasonically so that surface contamination was avoided. Immediately before each test the tank was rinsed with a solution of distilled water, dried in a warm air dryer, and then rinsed with the test liquid. After rinsing, the tank was filled to the desired liquid level with a syringe, hermetically sealed, and mounted on the test vehicle.

The entire test vehicle was balanced and the cradle on which the test tank was mounted was leveled to ensure that the ellipsoidal tank was oriented properly before and during the drop. After the tank was mounted and the vehicle balanced, the entire drop package was suspended from the top of the facility. The facility vacuum chamber was then closed and pumped down and the drop package was released. At package release the lights and the motion picture camera were activated. Approximately $2 \mathrm{sec}$ after release lateral acceleration was applied to the experimental apparatus, and the test tank traversed the linear bearing. 
Data Analysis

The data obtained in this investigation were collected during the free-fall period by a highspeed motion picture camera. Information on the zero-gravity liquid-vapor interface configuration was taken from the film by using a film analyzer. From the analyzer the observed interface shape could be directly plotted at various times throughout the drop. In the test films the general outline of the interface was defined by a dark band. The points used for plotting the interface shape followed the outer perimeter of this dark band (Fig. 6). Because of symmetry of the interface about the ellipsoid centerline before and during the drop, this outer perimeter corresponded to the part of the interface located in the plane defined by the ellipsoid centerline and the tank minor axis.

This observed interface, however, became distorted by refraction effects and at times because of the angle at which the camera viewed the test tank. The constantly present refraction of the observed interface was caused by the walls of the ellipsoidal tank and a layer of test liquid. Another form of distortion was created when the container was moved during a drop. When this occurred, the tank started at one end of the linear bearing track and traveled to the other end. The camera did not move with the tank (because of hardware limitations discussed previously) but instead was mounted approximately halfway along the distance the test tank traveled. This caused a parallax effect when the tank was not at the center of the track. It was possible to correct for the refraction error alone by using a calibration grid from which actual interface coordinates could be determined (see Ref. 3 for a detailed explanation). Correcting for parallax effects in combination with refraction, however, was not possible. Therefore, when the test tank was near the ends of the track, an approximate, or qualitative, liquid-vapor interface (location and configuration) was determined by studying the test film and using the calibration grid. When the tank was near the middle of the track and was positioned along the optical axis of the camera lens, the calibration grid could be employed to obtain an actual interface configuration.

In addition to the liquid-vapor interface plot the lateral acceleration characteristics of the tank were also obtained from the test film. This was accomplished by recording lateral displacement versus time data from the film. Two pointers (Fig. 3 ) were attached to the tank and used for reading displacement measurements. One pointer was aligned with the camera centerline when the tank was at the far end of the track before the application of the impulsive acceleration. The other pointer became centered in the camera's field of view as the tank traveled across the linear bearing track. The use of two pointers and a correction for parallax effects allowed for accurate displacement readings regardless of the location of the tank.

Accurate knowledge of the time the tank first started to accelerate was critical in correlating the initial displacement characteristics with time. In this investigation the starting time was indicated by illumination of a light-emitting diode. This light-emitting diode was activated when the retaining pin was rotated away from the tank base, allowing the air piston to accelerate the tank. Since the stroke of the piston was usually adjusted to only $1.27 \mathrm{~cm}$, the tank experienced a lateral acceleration for 0.1 to $0.2 \mathrm{sec}$.

The magnitude of the acceleration was determined by plotting displacement (DISP) versus time points on log-log graph paper. A curve was fitted to these points by using a slope of 2; the acceleration (ACC) was then obtained from the appropriate intercept of the curve (Fig. 7 is a typical plot). After the piston reached the end of its stroke, the acceleration value went to zero and the velocity of the test tank remained nearly constant. This velocity was determined by plotting displacement versus time and taking the slope of the plot (Fig. 8).

The variation of experimental conditions encompassed by the five tests conducted as part of this program and the anticipated shuttle/Centaur deployment conditions are shown in Table II. Also included in Table II are the calculated values of the test tank accelerations and the total time of the accelerating impulses.

\section{Test Results and Discussion}

In order to understand the problems associated with the dynamics of low-gravity liquidvapor systems in ellipsoidal tanks, the initial liquid-vapor interface location before any disturbance must be known. The initial phase of the test program was performed with the objective of determining equilibrium zero-gravity interface configurations that could exist in an ellipsoid. During this first phase of the study the test tank was not given an acceleration but instead was clamped to the linear bearing in a fixed position such that the tank was aligned with the optical axis of the motion picture camera (Fig. 2). The zero-gravity environment (drag on the experimental package has an insignificant effect on the results), coupled with solid-liquid-vapor combinations that produced near $0^{\circ}$ static contact angles, resulted in spherical liquid-vapor interface shapes inside the ellipsoidal tank. The experimental work that established equilibrium zero-gravity liquid-vapor interface shapes and locations is discussed in detail in Ref. 2 .

The results described in Ref. 2 indicate that, depending on the size of the vapor bubble, the liquid-vapor interface can exist at several locations in an ellipsoidal tank. This is true as long as the interface is able to meet the minimum energy requirement by forming a sphere within the walls of the tank. For the shuttle/Centaur separation dynamics problem, only liquid fill levels greater than 70 percent were of interest. Liquid fill levels of 80 percent or more resulted in vapor bubbles with diameters small enough so that they could be accommodated anywhere within the tank boundaries. As the interface radius of curvature increased with reduced fill levels, between 80 and 70 percent, the vapor bubble tended to form in the center of the ellipsoidal tank since this was the only location where a spherical bubble could fit within the tank boundaries.

After a better understanding of the equilibrium zero-gravity interface configurations had been acquired, 2 the experimental investigation 
continued by applying a lateral acceleration to the ellipsoidal tank. The orientation of the tank relative to the gravitational vector (Fig. 9) was selected so that the resulting zero-gravity vapor bubble would be at the assumed worst-case location (i.e., at the farthest extreme from the center of the tank, thus providing a maximum center-ofgravity offset) before the start of the impulsive acceleration for tests 1,2 , and 3 . Test conditions, liquids, and fill levels were chosen so that the time to form a nearly quiescent interface was as short as possible; usually less than $2 \mathrm{sec}$. During the test sequence the start of the lateral acceleration was delayed by 2.0 to $2.5 \mathrm{sec}$ to allow the liquid-vapor interface to form its zero Bond number configuration. This formation period was sufficiently short to allow adequate time to view the lateral acceleration of the test tank and the resulting motion of the tank and the test fluid.

Figures 9 and 10 show a sequence of pictures from one of the zero-gravity tests (test 1 , Table II) in which the ellipsoidal tank was accelerated. In Fig. 9 the first portion of the drop can be seen. This part of the drop involved the formation of a stable liquid-vapor interface. The initial condition of the experimental drop package was such that the liquid bottomed in the tank and was symmetric about the container major axis (Fig. 9(a)). Upon entry into the low-gravity environment the liquid-vapor interface underwent an oscillatory motion but remained symmetric about the ellipsoid major axis (Fig. 9(b)). This transient motion displaced the bubble along the major axis (Fig. 9(c)) to the other side of the tank, where the liquid motion damped and the vapor bubble became stable (Fig. $9(d)$ ). The process just described was well understood from the first phase of the experimental work and took approximately $2.5 \mathrm{sec}$.

Once the interface became quiescent, the 1 ateral acceleration was applied to the test tank. Just after the acceleration was applied, the vapor bubble started to move from the center of the tank toward the left wall (Fig. 10(a)). (The force was applied to the right side of the tank as viewed from the camera.) After the force had been applied for approximately $0.1 \mathrm{sec}$, a geyser appeared to form and the vapor bubble became highly deformed (Fig. 10(b). When the piston reached the end of its stroke and the applied force was no longer present, the geyser collapsed - leaving an interface that appeared to have no distinct shape (Fig. 10(c)). However, in a very short time (approximately $0.4 \mathrm{sec}$ ) after the acceleration became zero, the interface again appeared to be dominated by capillary forces and started to take on a spherical shape (Fig. 10(d)). As the ellipsoidal tank continued to move across the track, the interface traveled from the left side to the right side of the tank (Fig. 10(e)). Toward the end of the drop period the liquid motion damped, and the liquid-vapor interface appeared to be forming its equilibrium spherical zero-gravity configuration (Fig. 10(f)).

Figure 11 shows plots of the liquid-vapor interface corresponding to some of the photographs just described. Figure 11(a) illustrates the initial condition of the low-gravity interface before any impulse. This plot was derived from the first phase of the experimental program. Figures 11 (b) and (d) correspond to times when the interface was distorted due to refraction and parallax and therefore are qualitative interpretations of the observed interface (determined as described in the section "Data Analysis"). A more accurate interface shape was plotted when the tank was near the middle of the track (Fig. 11(c)). Note that this plot is not complete, however, because refraction was particularly high near the edge of the ellipsoidal tank.

Four other impulsive acceleration runs were performed and each run had similar results. Figures 12 to 15 are plots, similar to Fig. 11, of the liquid-vapor interface configuration at key times during test runs 2 to 5 , respectively. In every run but one (test 3 , which had the lowest impulsive acceleration) a geyser formed, and in all tests the vapor bubble remained intact and was becoming stable near the end of the test period.

This part of the program was performed to provide data for the verification of a computer code and did not actually scale Centaur tank configuration or flight conditions. Time constraints permitted only a limited number of tests to be made. Consequentiy no attempt was made to develop correlating parameters relating the influence of the impulsive lateral acceleration to the observed behavior of the liquid and the vapor within the test tank.

\section{Numerical Modeling}

The NASA-VOF 3D computer code ${ }^{4}$ was used to provide (1) an analytical comparison with the results from three of the previously described tests, thus providing a variation in both liquid fill level and fluid properties, and (2) an analytical prediction of the Centaur liquid oxygen motion resulting from the deployment of the vehicle from the shuttle cargo bay, assuming a worst-case initial location for the vapor bubble. The NASA-VOF3D program simulates three-dimensional incompressible flows with free surfaces by using the volume-offluid algorithm. It is specifically designed to predict liquid flows in a low-gravity environment, where the free surface physics must be accurately treated. The computational technique is based on the use of donor-acceptor differencing to track the free surface across an Eulerian grid.

NASA-VOF 30 is the latest of a family of computer codes developed at the Los Alamos National Laboratory under an interagency agreement with NASA Lewis $\$^{*}$. The first of these codes, NASA SOLA-VOF, ${ }^{5}$ is a two-dimensional program written specifically for simulating the axisymmetric draining of spacecraft propellant tanks. The recently released NASA-VOF2 ${ }^{6}$ and NASA-VOF3D programs contain several improvements over the NASA SOLA-VOF code.

*All three computer codes are available, for a nominal fee, from the National Energy Software Center, Argonne National Laboratory, Argonne, Illinois. 
The NASA-VOF3D program, like its NASA-VOF20 predecessor, is highly structured so that individual components may be easily modified to fit specific problems or to accept subsequent code upgrades. This approach allows greater efficiency in operation, simplifies problem setup, and facilitates code modification. Although NASA-VOF3D can run many problems without alteration, a specific application will generally require program alterations for special inflow or outflow ports, complicated geometries, or unusual initial conditions. Seldom does anything have to be deleted; rather the modifications are usually additions to the existing structure.

Because much of the numerical methodology is very similar in two and three dimensions, the reader will frequently be referred to the NASA-VOF2D report ${ }^{6}$ for a fuller description of topics mentioned in this paper. In particular, Ref. 6 discusses the developments leading to the use of SOLA-VOF methodology in low-gravity liquid flows. NASA-VOF 30 incorporates the NASA-VOF 2D improvements in donor-acceptor differencing, in the ability to accurately model curved boundaries, and in the inclusion of a conjugate residual option as well as a successive-overrelaxation (SOR) option for advancing the pressures (and velocities) in time throughout the computing mesh. The conjugate residual method is vectorized for the cray computer and employs a scaled coefficient matrix. It was found to be necessary for accuracy to radically alter the procedure for calculating threedimensional surface tension effects, as will be explained in the following section.

The basic NASA-VOF algorithm is based on the solution of the Navier-Stokes equations for an incompressible fluid. These equations apply at every point inside the fluid. The complete Navier-Stokes equations for an incompressible fluid are solved by finite differences, with the surface tension effects included. Several sets of quantities must be incremented to advance the calculation through one time step. One set of procedures is applied to all computational cells open to flow; other procedures are applied to fluid cells only, with alternative procedures for surface cells.

The free surfaces are treated by introducing a function $F$ that is defined to be unity at any point occupied by the liquid, and zero elsewhere. When averaged over a cell of the computing mesh, the value of $F$ represents the fractional volume of the cell occupied by liquid. Cells with $F$ values between one and zero are partially filled with liquid; they are either intersected by a free surface or contain voids (bubbles) smaller than cell mesh dimensions. The $F$ function is used to determine which cells contain a free surface boundary and where the liquid is located in the cells. Gradients of $F$ determine the mean local surface normal and together with $F$ values permit construction of an approximate interface. Surface tension and wall adhesion forces may then be computed. The special requirements for construction of gradients of the step function $F$ are discussed in Ref. 6 .

\section{Numerical Methodology}

This section briefly describes the numerical methods employed by the NASA-VOF computer codes.
Only the key features and limitations of the programs are presented; for more detail examine Refs. 4 and 6 . The programs use an Eulerian frame and allow for an arbitrary number of free surface segments with any reasonable shape. Variable mesh spacing is permitted in all coordinate directions, as is necessary for efficient numerical solution of many problems. However, the variable mesh capability is subject to reasonable requirements for avoiding neighboring cells of grossly different size and cells of large aspect ratio.

Typical boundary conditions for the computational mesh are imposed in a standard way by the use of flags denoting the tank walls. Other types of boundary conditions, if needed, must be supplied by the user and placed in a special subroutine. An example of the use of special boundary conditions (i.e., a tank drain hole) is contained in the NASA SOLA-VOF report. 5

The program specifies the location of obstacles and the initial locations of liquid, vapor, and liquid-vapor interfaces. When appropriate, a liquid-vapor interface may be calculated as an equilibrium surface; otherwise its shape must be specified by the user in advance.

The initial liquid velocities are specified as constant or zero. It would, in principle, be possible to take the liquid to be initially in nonuniform motion. However, it is very rare for a dynamic velocity field to be known with sufficient precision to be suitable as an initial condition. Although the pressure field is initially zeroed, this command may be overridden to produce a hydrostatic head as the system's initial pressure field. It is important that an accurate initial pressure field be employed since problems with poor initial pressure definition may have difficulty.

All the surface physics algorithms developed for NASA-VOF2D were improved and generalized during the development of the three-dimensional modeling capability. In two dimensions one surface curvature can be calculated algebraically, and one curvature must be computed by finitedifference approximations. Moreover the algebraically determined curvature is typically the larger one in the crucial near-axis cells. In three dimensions both surface curvatures must be computed by less accurate finite-difference approximations. In addition, considerable refinement of the two-dimensional surface tension algorithms was necessary during the development of the three-dimensional computer code. Reference 4 contains a detailed discussion of how these surface physics effects were accounted for numerically.

Considerable effort was expended in obtaining a realistic wall adhesion algorithm for twodimensional problems (it is a standard feature of NASA-VOF2D). This turned out to be of crucial importance in calculating such flow features as the leading-edge liquid velocity in a propellant reorientation problem. In two dimensions the task was accomplished (1) by defining a cell index array that specifies whether the wall adhesion option or the surface tension option is to be selected and (2) by defining angles, consistent with the tank geometry, that determine the direction in which any wall adhesion force is to act. 
In two dimensions the wall adhesion calculation is simplified because the force points either up or down the tank wall. This approach neglects the effect of liquid contact angle since the contact angle is usually very smal1. In contrast, a successful three-dimensional algorithm must introduce an additional angle, redefined for each computational cycle, that determines in what direction the wall-adhesion force is to point.

The present version of the three-dimensional program does not permit the accurate calculation of wall adhesion except for straight-walled cells; in general, it forces the cell indicator flags to choose the surface tension option. The inclusion of a realistic wall adhesion calculation into the surface physics routines is one of the principal tasks that must be accomplished if NASA-VOF 30 is to evolve into a truly general-purpose code. However, it is emphasized that the present program still has a very significant range of applicability that permits a wide range of design questions to be meaningfully addressed. For example, questions concerning the bulk motion of fluid in a given geometry may be addressed without the interaction of the liquid and its tank wall being predicted with high accuracy.

\section{Analytical Results and Discussion}

Three of the Zero-Gravity Facility tests (tests 1, 4, and 5 in Table II) were numerically modeled. Inputs to the NASA-VOF3D computer code included liquid properties (Table I), tank geometry, vapor bubble size and location before the start of impulsive acceleration, and the duration, direction, and magnitude of the applied acceleration.

The results of the numerical modeling activity for test 1 are shown in Fig. 16 as crosssectional views through the center of the tank. The two-dimensional views of the vapor bubble and the liquid velocity vectors shown are a graphical output feature of the NASA-VOF 30 computer code. For each time step the liquid velocity vectors are scaled to the maximum liquid velocity at that time. The sequence in time of the first, third, and last cross-sectional views of the vapor bubble shown in Fig. 16 were selected to correspond approximately in time with the plots of the experimental data presented in Figs. 11(a) to (c). The numerical modeling was terminated at approximately $0.6 \mathrm{sec}$ (Fig. 16(f)) when significant vapor bubble motion was no longer observed and the vapor bubble began to break up.

The numerical modeling results corresponding to tests 4 and 5 are presented in Figs. 17 and 18, respectively. Once again, the sequence in time of the cross-sectional views of the vapor bubbles was chosen to correspond approximately in time with the plots of the liquid-vapor interfaces derived from the experimental data (Figs. 14 and 15).

Comparing the experimental data generated in the Lewis Zero-Gravity Facility with the NASAVOF 3D numerical modeling output led to the conclusion that the computer code could be used to predict liquid-oxygen motion in the Centaur vehicle. Excellent agreement existed between the experimental and numerical results for the duration of the accelerating force. During this time most of the liquid motion took place and the highest liquid velocities were calculated. At later times, in contrast to the experimental observations, the numerically generated ullage fragmented, probably reflecting the continuing difficulty in accurately modeling surface-tension-dominated fluid dynamic phenomena. However, before the ullage broke up, the liquid motion had significantly subsided, as observed experimentally and determined numerically. Since the liquid momentum flux was proportional to the square of the liquid velocity, this numerical inaccuracy should not affect the ultimate objective, the prediction of the liquidoxygen propellant and Centaur vehicle motion in response to an impulsive acceleration.

Similar to the numerical modeling of the experimental data from the Zero-Gravity Facility, the NASA-VOF3D computer code was employed to predict the liquid oxygen motion in the Centaur vehicle during a deployment maneuver. Inputs to the code included liquid-oxygen properties (Table I), the vapor bubble geometry and its assumed worst-case initial location (maximum displacement of the liquid center of gravity from the Centaur vehicle centerline), the tank geometry, and the characteristics of the applied acceleration (Table II).

The results of the NASA-VOF3D modeling effort for the shuttle/Centaur program are shown in Figs. 19 to 23. The left portion of each figure is a side view of the liquid-oxygen tank showing a cross section through the Centaur vehicle centerline. (Note that, in contrast with the oblate spheroid tank configuration used for the experimental tests, the shuttle/Centaur liquid-oxygen tank has been enlarged by the addition of a cylindrical midsection so that it appears to be nearly spherical.) The right side of each figure is a cross-sectional view of the tank that is perpendicular to the Centaur vehicle centerline and taken in a plane approximately one-third of the tank height from the top of the tank. Figure 19 shows the assumed worst-case initial location for the vapor bubble. One second after the start of the $0.44-\mathrm{sec}$ impulsive acceleration the liquid velocity reached a maximum of approximately $50 \mathrm{~cm} / \mathrm{sec}$ (Fig. 20). As time progressed (Figs. 21 to 23) the liquid velocities decayed and the vapor bubble became highly distorted, nearly separating into two distinct regions.

The numerical output of the NASA-VOF3D computer code included the prediction of the pressure distribution in the Centaur liquid-oxygen tank as well as the liquid velocity field shown graphically in Figs. 20 to 23 . These pressure distribution predictions can be employed in a vehicle dynamics analysis to establish the relative motion of the Centaur and shuttle vehicles during a deployment maneuver. For the first two planned Centaur-inshuttle missions, the launches of the Galileo and Ulysses spacecraft, no hazardous vehicle motion was predicted.

\section{Concluding Remarks}

The NASA Lewis Research Center, during the past two decades, has been a leading developer of low-gravity fluid management technology. Recent analytical and experimental efforts have addressed the potential problem associated with the separation of the Centaur vehicle from the shuttle 
orbiter. Experimental data obtained in the unique Lewis Zero-Gravity Facility were used to assess the capabilities of the NASA-VOF3D computer code, developed under an interagency agreement with the Los Alamos National Laboratory. The NASA-VOF3D program was then employed to predict the liquidoxygen propellant motion and pressure field within the Centaur tankage during the planned deployment maneuver.

Based on the experimental and analytical work performed it was concluded that no hazardous vehicle motion would have resulted from the Centaur separation maneuver if the propellant tanks were nearly full. Although the shuttle/Centaur development activity has been suspended, the problem solution presented serves to illustrate the capabilities of the NASA-VOF3D computer code and the ability of Lewis to provide timely fluid management technology information to developers of advanced space systems.

\section{References}

1. Aydelott, J.C., Carney, M.J., and Hochstein, J.I., "NASA Lewis Research Center Low-Gravity Fluid Management Technology Program," NASA TM-87145, 1985. (Also, AIAA/GNOS-85-002.)
2. Salzman, J.A., "Low-Gravity Liquid-Vapor Interface Configurations in Spheroidal Containers," NASA TN D-5648, 1970.

3. Carney, M.J., "Liquid-Vapor Interface Locations in a Spheroidal Container Under Low Gravity," NASA TM-87147, 1986.

4. Torrey, M.D., Mjolsness, R.C., and Stein, L.R., "NASA-VOF3D: A Computer Program for ThreeDimensional Incompressible Flows with Free Surfaces," LA-11009-MS, 1987. (To be published.)

5. Hotchkiss, R.S., "Simulation of Tank Draining Phenomena with the NASA SOLA-VOF Code," LA-8163-MS, Dec. 1979.

6. Torrey, M.D., Cloutman, L.D., Mjolsness, R.C., and Hirt, C.W., "NASA-VOF2D: A Computer Program for Incompressible Flows with Free Surfaces," LA-10612-MS, 1985.

7. "Shuttle/Centaur G-Prime Phase III Safety Review Package - Book 2, Airborne Technical Description," Report No. GDSS-SSC-85-007, General Dynamics Space Systems Division, San Diego, CA, Dec. 1985.

TABLE I. - LIQUID PROPERTIES

\begin{tabular}{|c|c|c|c|}
\hline Liquid & $\begin{array}{c}\text { Surface } \\
\text { tension, } \\
\text { dyn/cm }\end{array}$ & $\begin{array}{c}\text { Densityy, } \\
\mathrm{g} / \mathrm{cm}^{3}\end{array}$ & $\begin{array}{c}\text { Dynamic } \\
\text { viscosity, } \\
\mathrm{CP}\end{array}$ \\
\hline $\begin{array}{c}\text { Ethanol } \\
\left(\text { at } 20^{\circ} \mathrm{C}\right)\end{array}$ & 22.3 & 0.79 & 1.20 \\
$\begin{array}{c}\mathrm{FC}-43 \\
\left(\text { at } 20.5^{\circ} \mathrm{C}\right)\end{array}$ & 16.8 & 1.90 & 6.41 \\
$\begin{array}{c}\text { Liquid oxygen } \\
\text { (at -180 }\end{array}$ & 10.0 & 1.07 & .19 \\
\hline
\end{tabular}

TABLE II. - SUMMARY OF ZERO-GRAVITY FACILITY EXPERIMENTAL CONDITIONS AND ANTICIPATED SHUTTLE/CENTAUR DEPLOYMENT CONDITIONS FOR GALILEO MISSION

\begin{tabular}{|c|c|c|c|c|}
\hline Test & Liquid & $\begin{array}{c}\text { Fill } \\
\text { level, } \\
\text { percent }\end{array}$ & $\begin{array}{c}\text { Applied } \\
\text { acceleration, } \\
\text { g }\end{array}$ & $\begin{array}{c}\text { Time } \\
\text { acceleration } \\
\text { applied, } \\
\text { sec }\end{array}$ \\
\hline 1 & Ethanol & 90 & 0.25 & 0.101 \\
2 & 90 & .22 & .108 \\
3 & 90 & .10 & .160 \\
4 & & 75 & .22 & .109 \\
5 & FC-43 & 90 & .14 & .132 \\
\hline Shuttle/Centaur & Liquid & 89 & 90.133 & 0.440 \\
\hline
\end{tabular}

a Maximum value (applied acceleration $=0.133 \cos 3.47 \mathrm{t}$, where $t$ denotes time in seconds.) 


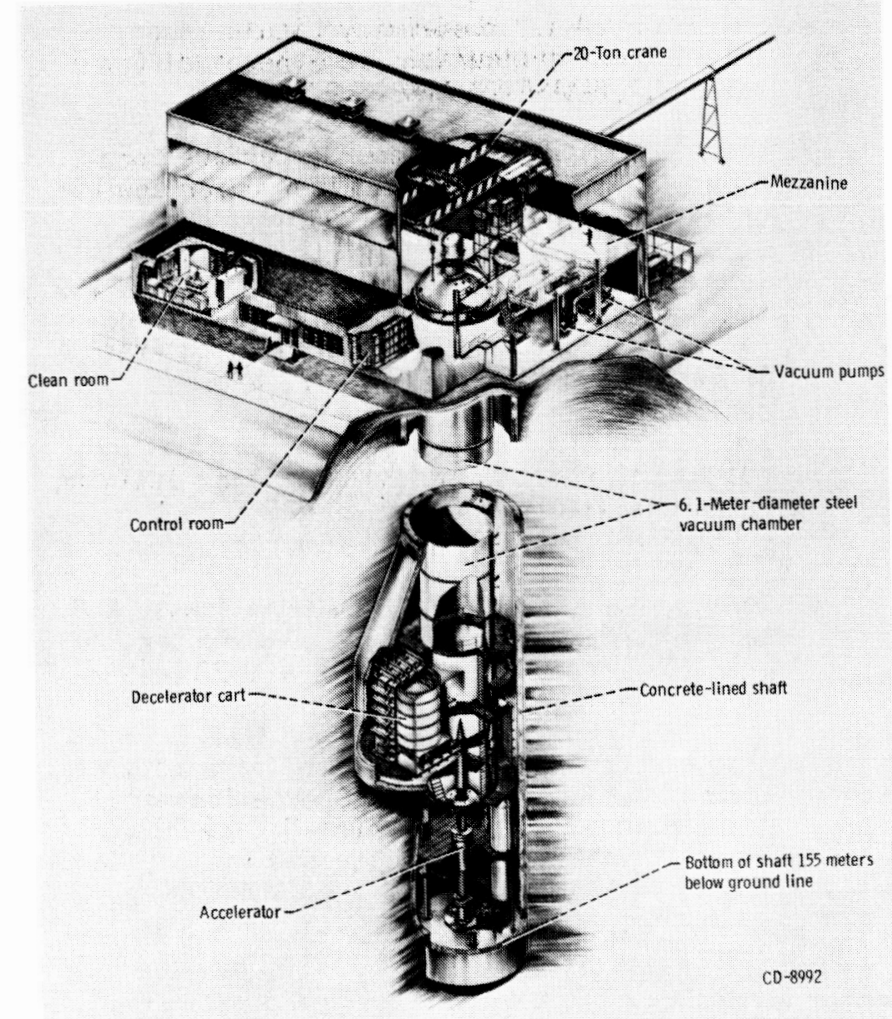

FigURE 1. - NASA LEWIS RESEARCH CENTER ZERO GRAVITY FACILITY.

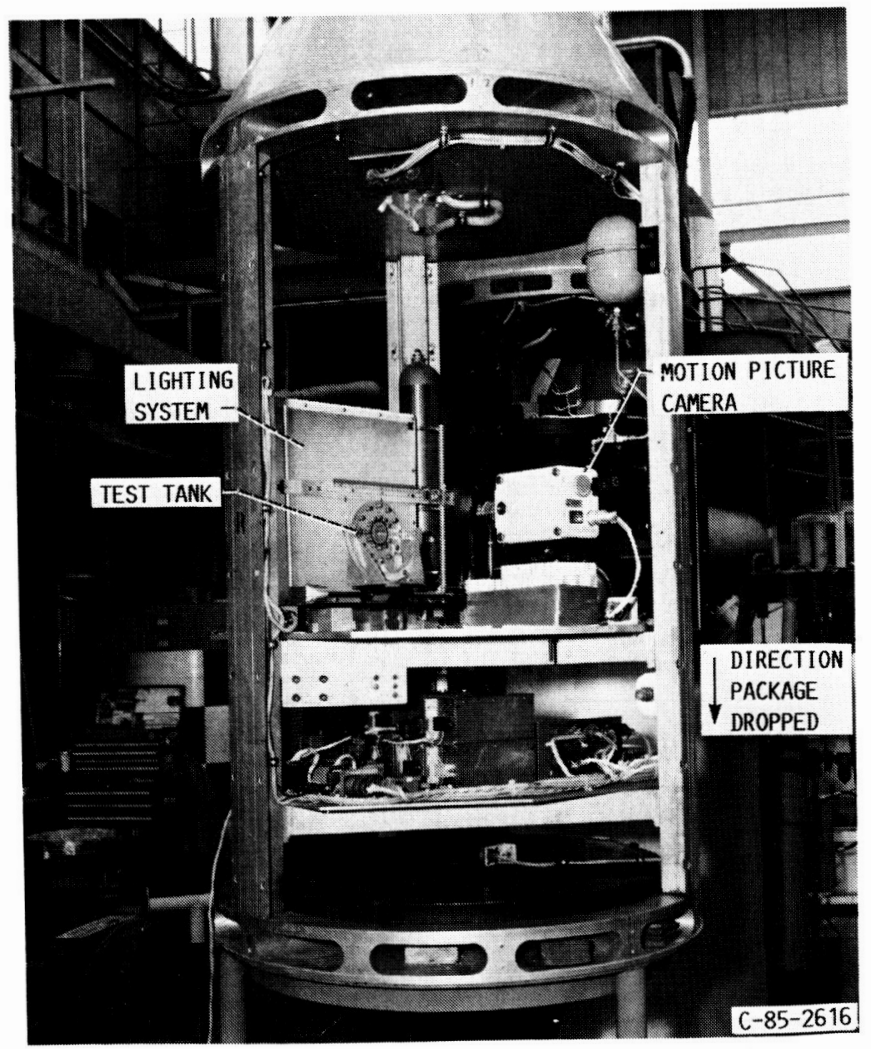

FIGURE 2. - ZERO-GRAVITY FACILITY EXPERIMENTAL DROP PACKAGE.

\section{ORIGINAL PAGE IS OF POOR QUALITY}

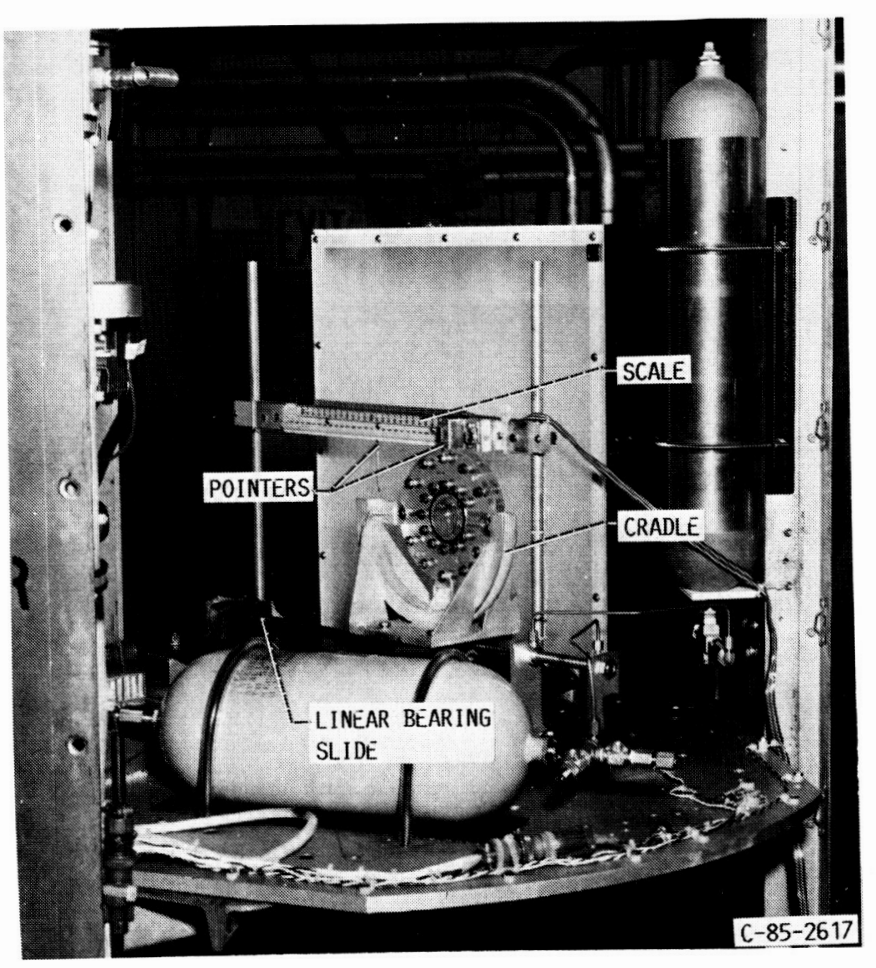

FIGURE 3. - EXPERIMENTAL APPARATUS MOUNTED ON TEST TRAY. 


\section{ORIGINAL PAGE IS \\ OF POOR QUALITY}

TIMER AND SEQUENCER

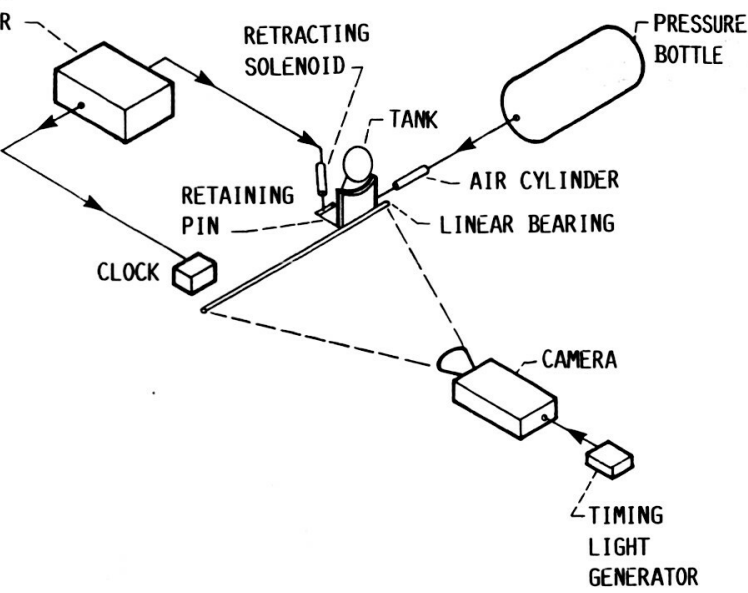

FIGURE 4. - SCHEMATIC OF EXPERIMENTAL APPARATUS.
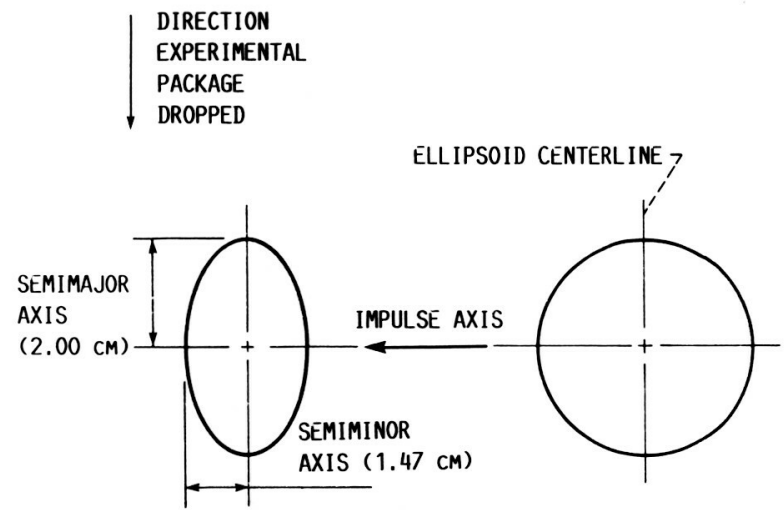

FRONT VIEW RELATIVE TO CAMERA

SIDE VIEW RELATIVE TO CAMERA

FIGURE 5. - ELLIPSOIDAL CONFIGURATION OF MODEL TANK.

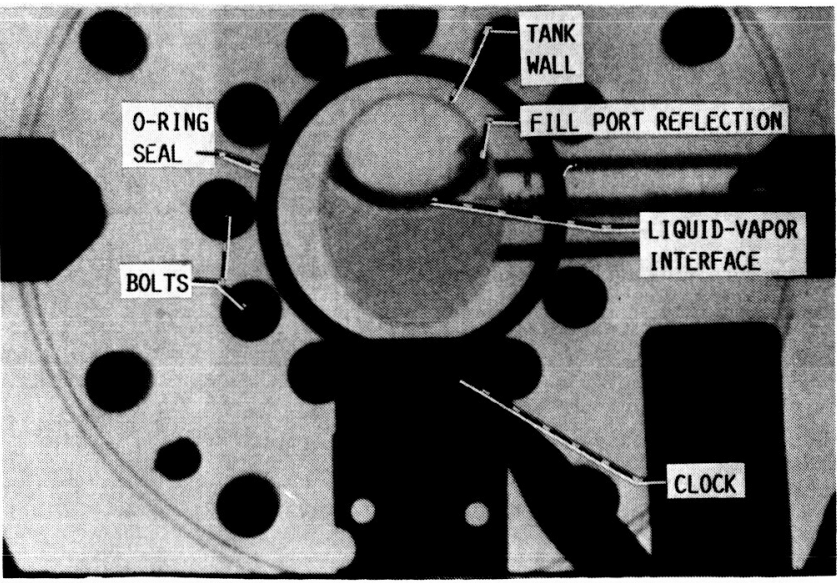

FIGURE 6. - EQUILIBRIUM LIQUID-VAPOR INTERFACE CONFIGURATION IN ELLIPSOIDAL TANK. BOND NUMBER, 0; FILL LEVEL. 80 PERCENT.

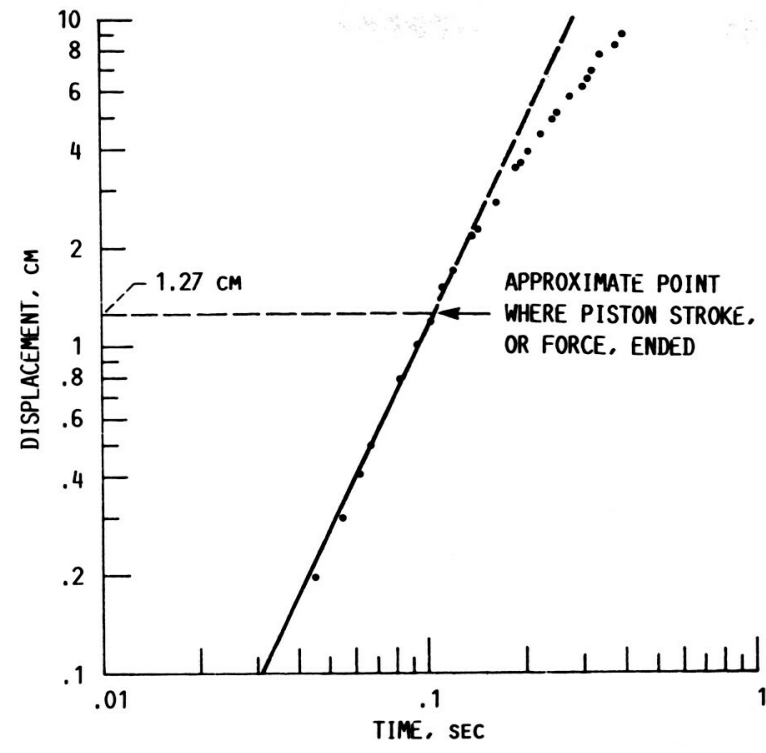

FIGURE 7. - REPRESENTATIVE LATERAL ACCELERATION CHARACTERISTICS USING ASSUMED SLOPE OF 2. LATERAL ACCELERATION FOR THIS PLOT, $0.22 \mathrm{~g}$.

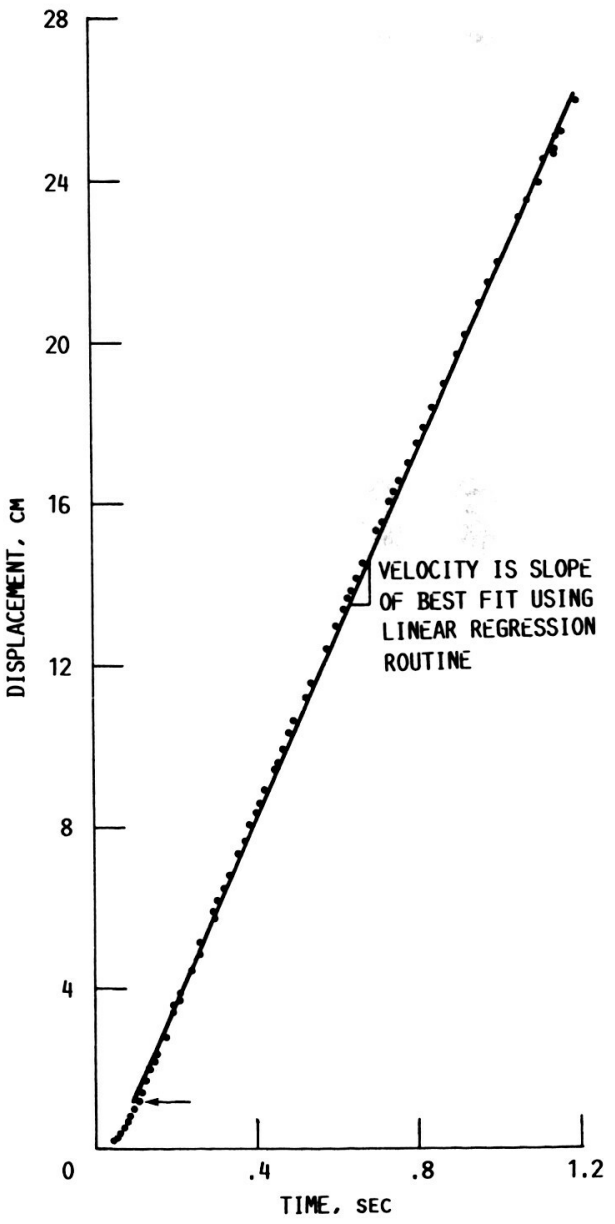

FIGURE 8. - REPRESENTATIVE LATERAL VELOCITY CHARACTERISTIC. LATERAL VELOCITY FOR THIS PLOT. $22.9 \mathrm{cM} / \mathrm{SEC}$. 


\section{ORIGINAL PAGE IS \\ OF. POOR QUALITY}

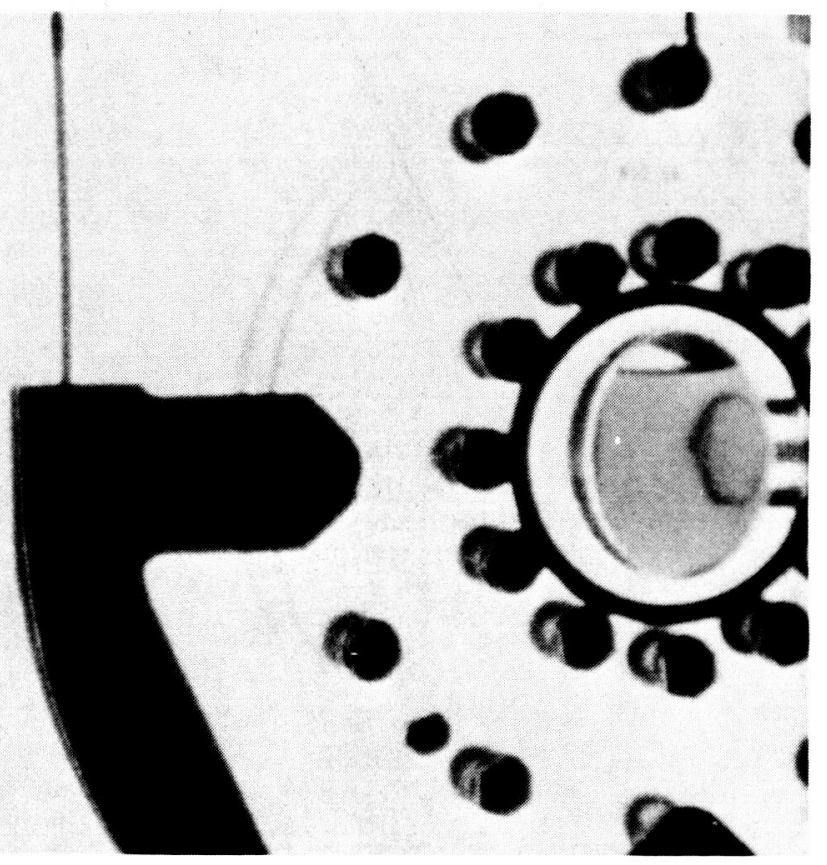

(A) INITIAL LIQUID-VAPOR INTERFACE CONFIGURATION; TIME, 0 SEC.

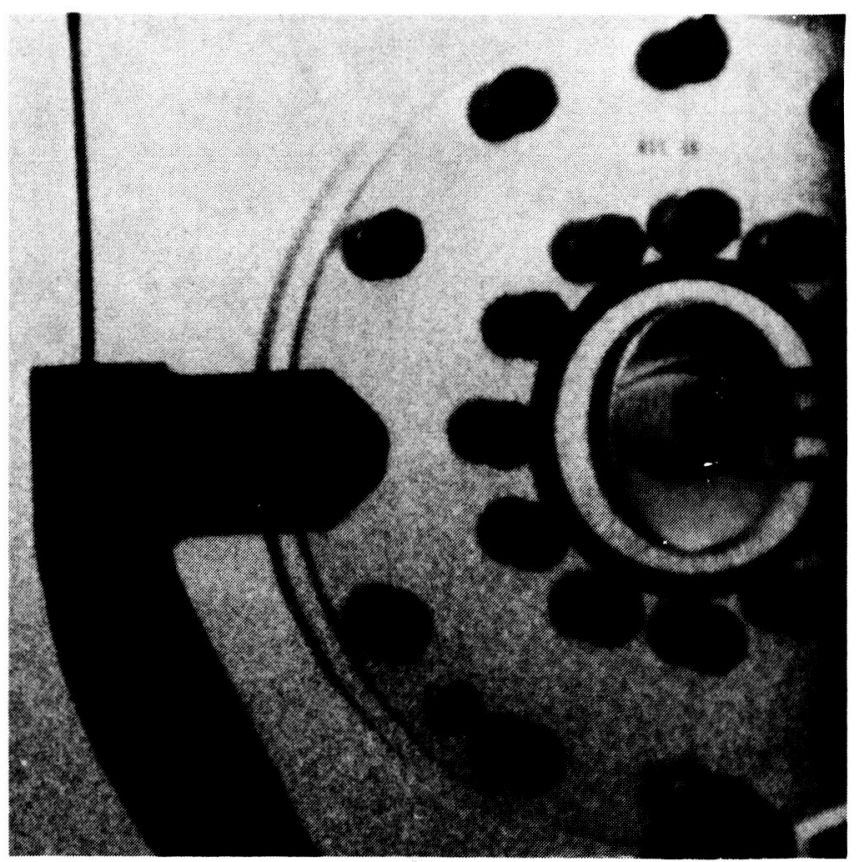

(C) DISPLACEMENT OF INTERFACE ALONG TANK MAJOR AXIS: TIME, 0.39 SEC INTO DROP.

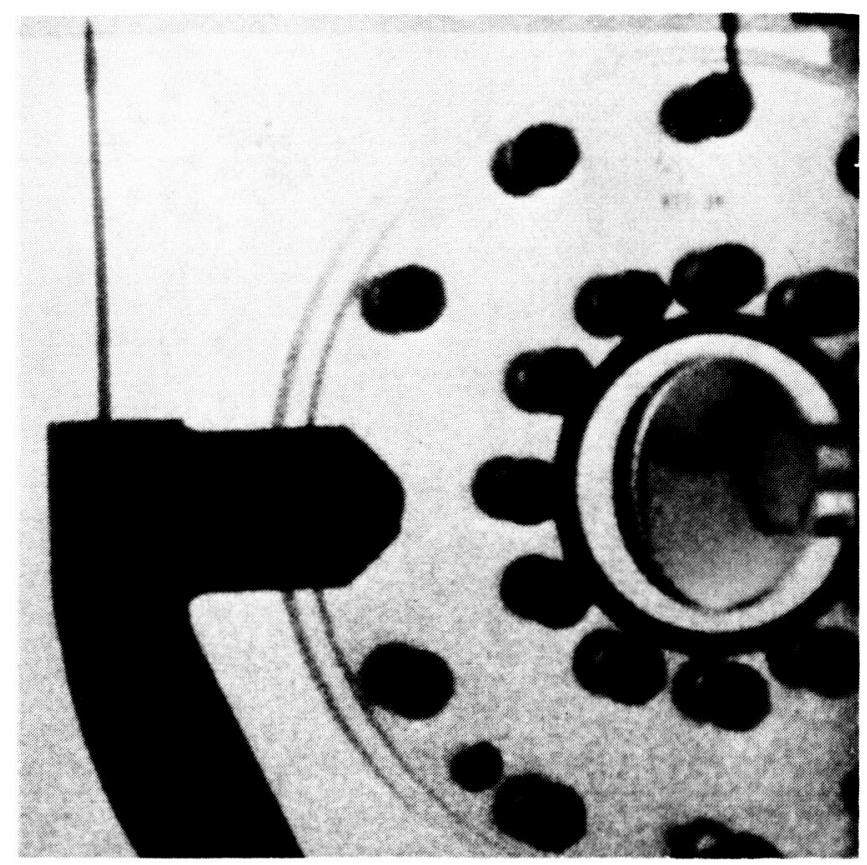

(B) TRANSIENT INTERFACE SHAPE: TIME, 0.09 SEC INTO DROP.

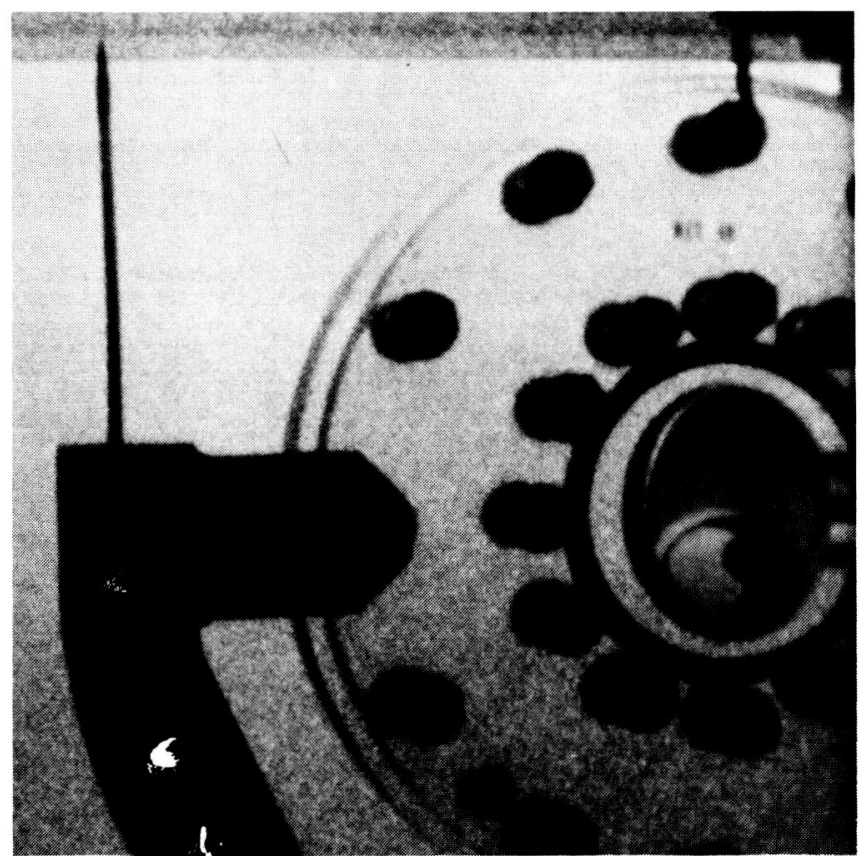

(D) EQUILIBRIUM ZERO-GRAVITY INTERFACE CONFIGURATION; TIME, 2.50 SEC INTO DROP.

FIGURE 9. - TRANSIENT MOTION OF INTERFACE UPON ENTERING LOW GRAVITY. FILL LEVEL, 90 PERCENT.| (TANK MAJOR AXIS PARALLEL tO DROP DIRECTION.) 


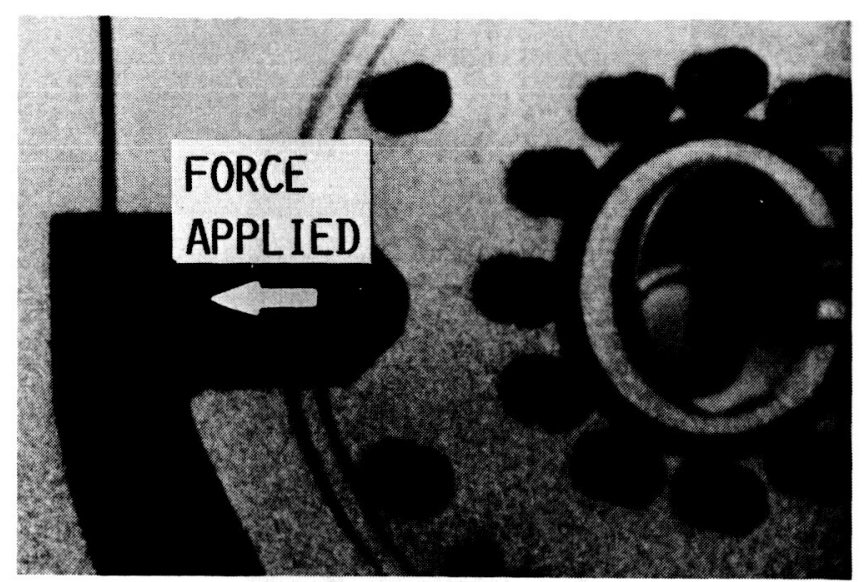

(A) INITIAL MOTION OF INTERFACE; TIME, 0.06 sEC.

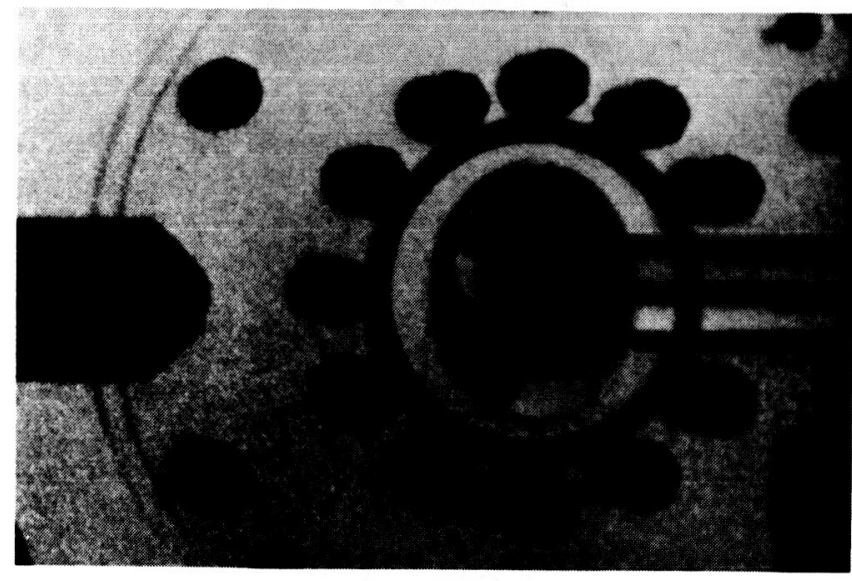

(C) MAXIMUM INTERFACE DISTORTION: TIME, 0.18 SEC.

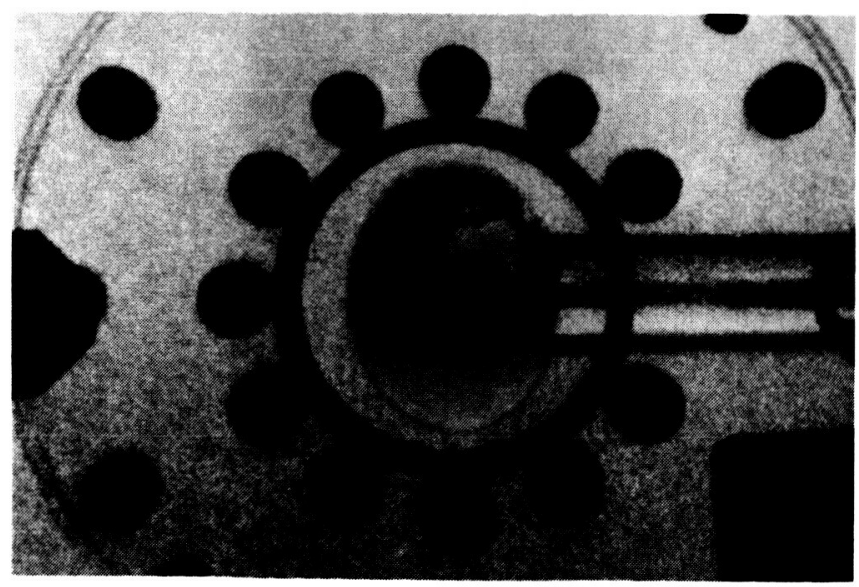

(E) MOVEMENT OF INTERFACE ALONG TANK MAJOR AXIS DURING CONSTANTVELOCITY PERIOD OF TANK MOTION: TIME, $0.62 \mathrm{sEC}$.

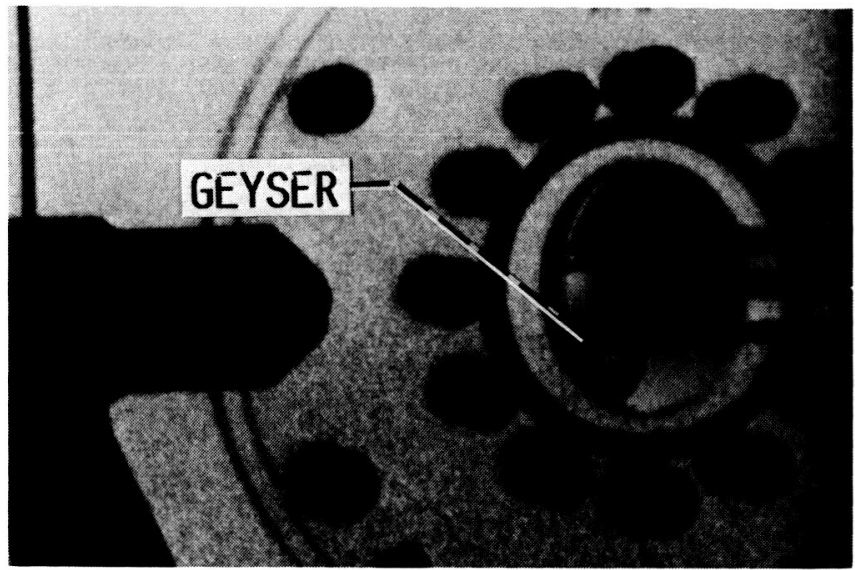

(B) GEYSER FORMATION: TIME, $0.10 \mathrm{sEC}$.

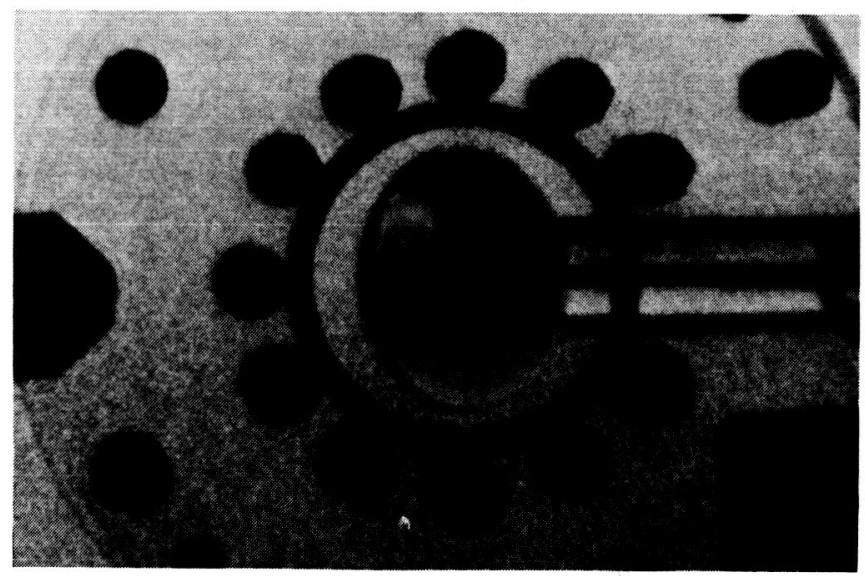

(D) TRANSIENT INTERFACE SHAPE AFTER ACCELERATION ENDS; TIME, 0.40 SEC.

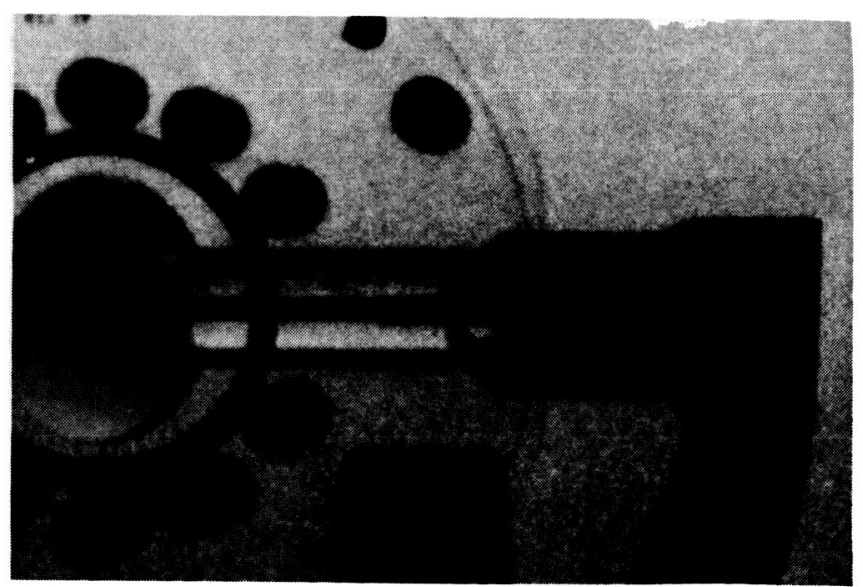

(F) INTERFACE AGAIN DOMINATED BY CAPILLARY FORCES; TIME, 1.09 SEC.

FigURE 10. - LIQUID-VAPOR INTERFACE CONFIGURATION DURING AND AFTER IMPULSIVE ACCELERATION. TEST 1; FILL LEVEL, 90 PERCENT; IMPULSE, 0.25g FOR $0.101 \mathrm{sEC}$. (TIME MEASURED FROM START OF IMPULSIVE ACCELERATION.) 


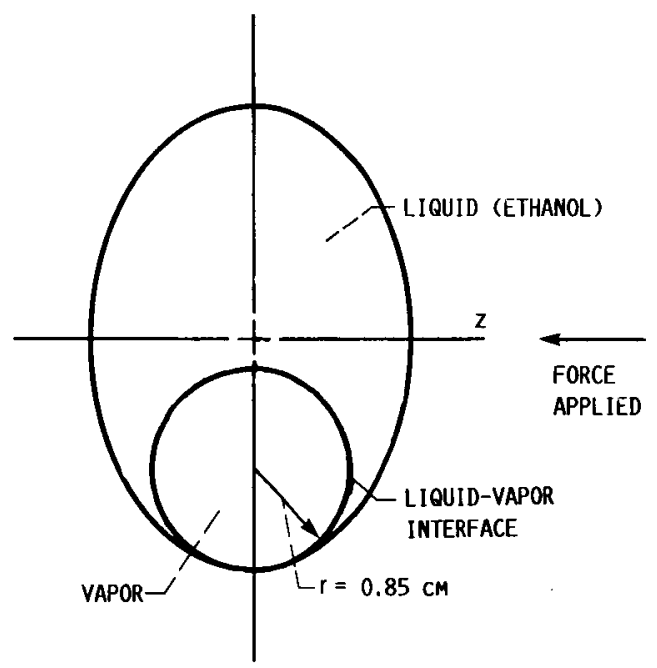

(A) EQUILIBRIUM ZERO-GRAVITY CONFIGURATION.

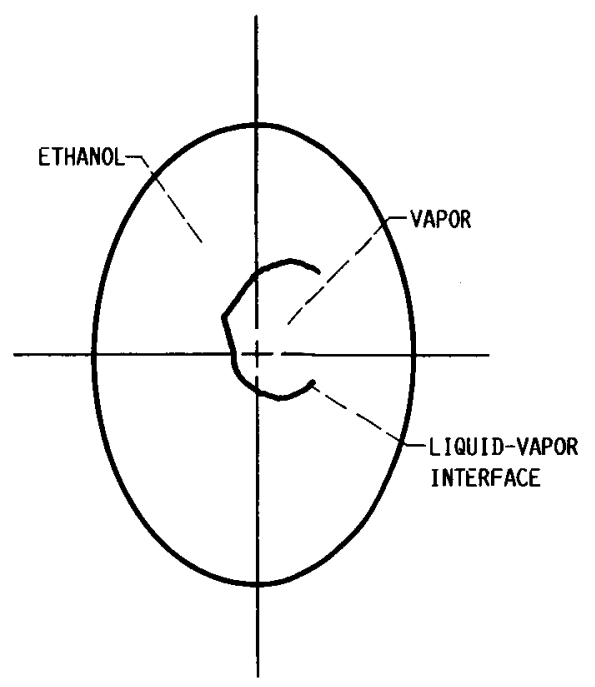

(C) QUANTITATIVE VIEW OF LIQUID-VAPOR INTERFACE: TIME, 0.62 SEC.

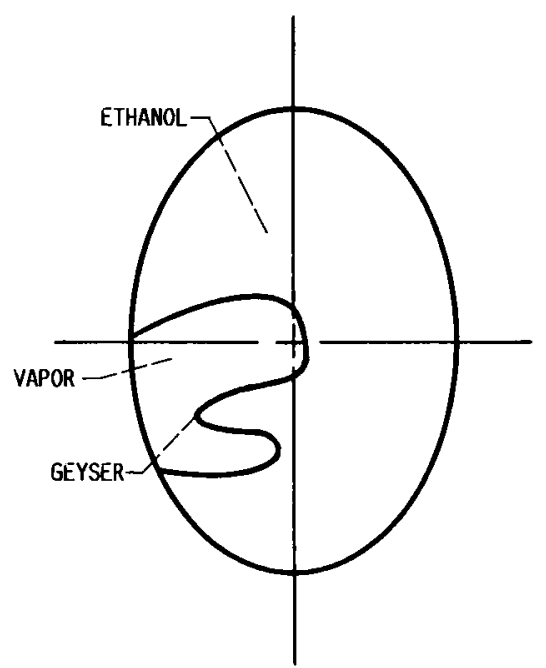

(B) QUALITATIVE VIEW OF LIQUID-VAPOR INTERFACE: TIME, 0.10 SEC.

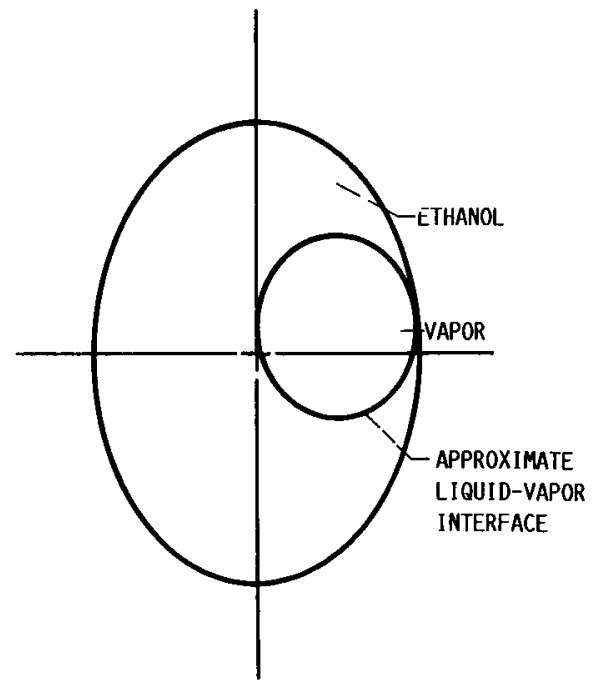

(D) QUALITATIVE VIEW OF LIQUID-VAPOR INTERFACE: TIME, $1.09 \mathrm{SEC}$.

FIgURE 11. - PLOTS OF LIQUID-VAPOR INTERFACE CONFIGURATION - TEST 1 . FILL LEVEL, 90 PERCENT: 'IMPULSE, $0.25 \mathrm{~g}$ FOR 0.101 SEC. (TIME MEASURED FROM START OF IMPULSIVE ACCELERATION. ) 


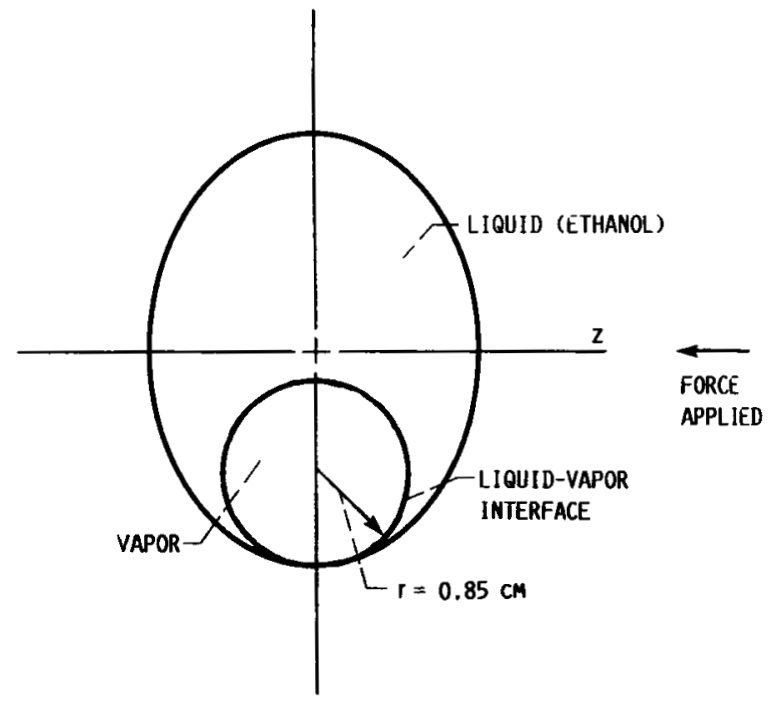

(A) EQUILIBRIUM ZERO-GRAVITY CONFIGURATION.

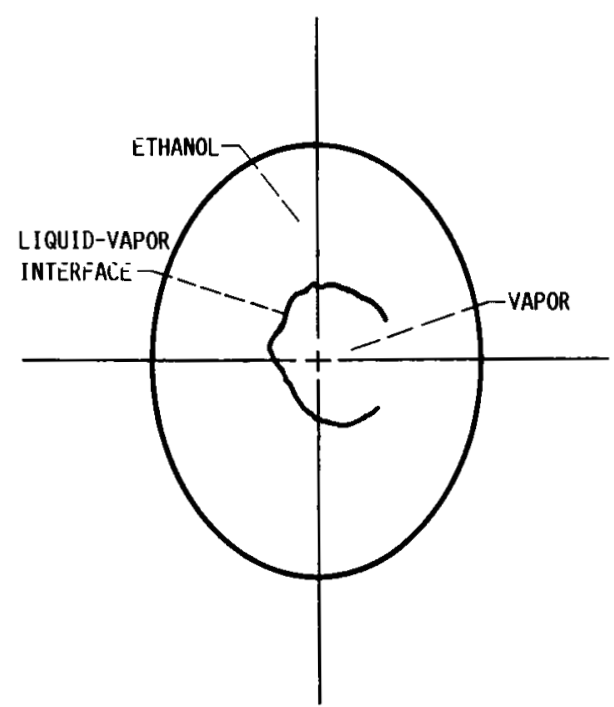

(C) QUANTITATIVE VIEW OF LIQUID-VAPOR INTERFACE:

TIME, 0.69 SEC.

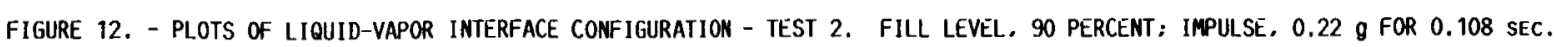
(TIME MEASURED FROM START OF IMPULSIVE ACCELERATION.)

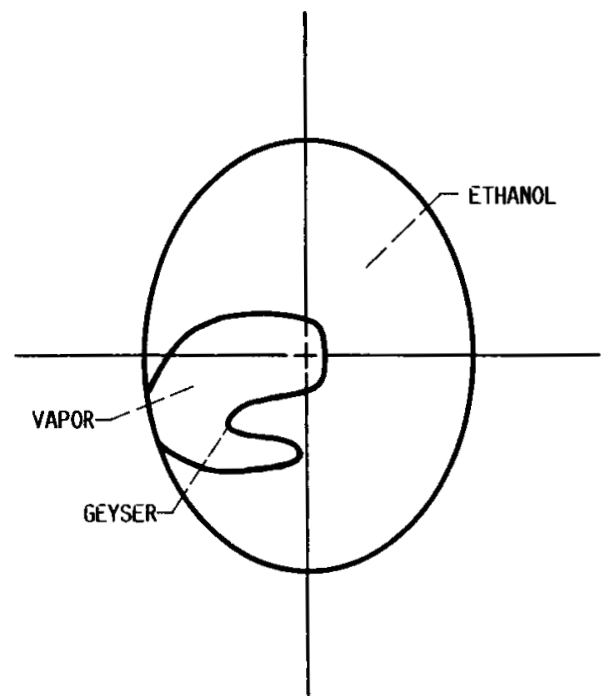

(B) QUALITATIVE VIEW OF LIQUID-VAPOR INTERFACE, TIME, $0.10 \mathrm{SEC}$.

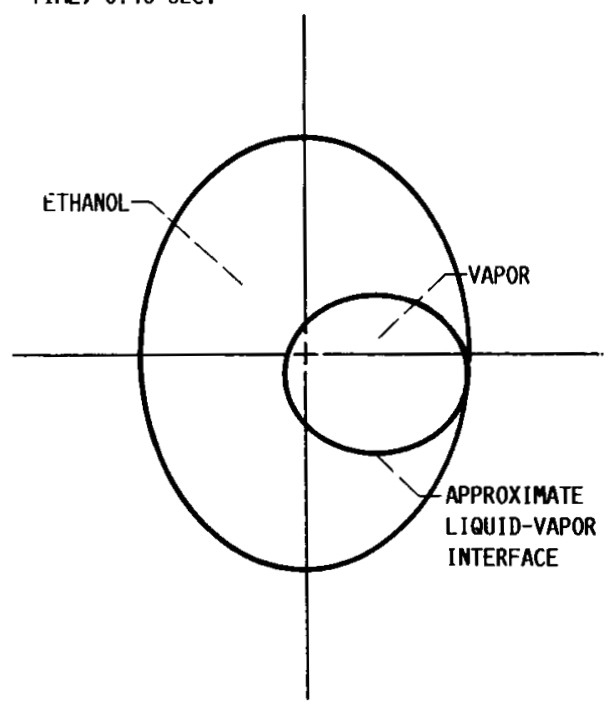

(D) QUALITATIVE VIEW OF LIQUID-VAPOR INTERFACE: TIME, 1.18 SEC. 


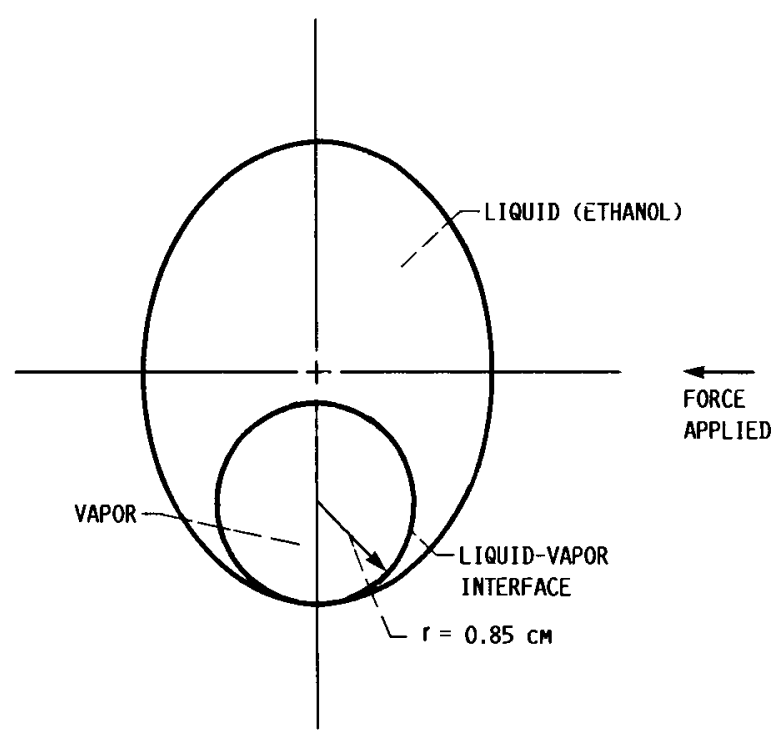

(A) EQUILIBRIUM ZERO-GRAVITY CONFIGURATION.

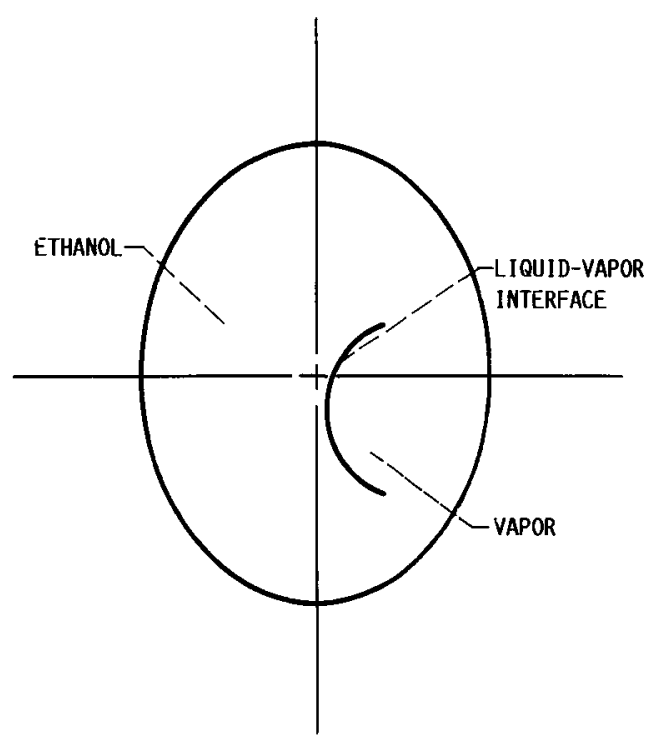

(C) QUANTITATIVE VIEW OF LIQUID-VAPOR INTERFACE:

TIME, 0.93 SEC.

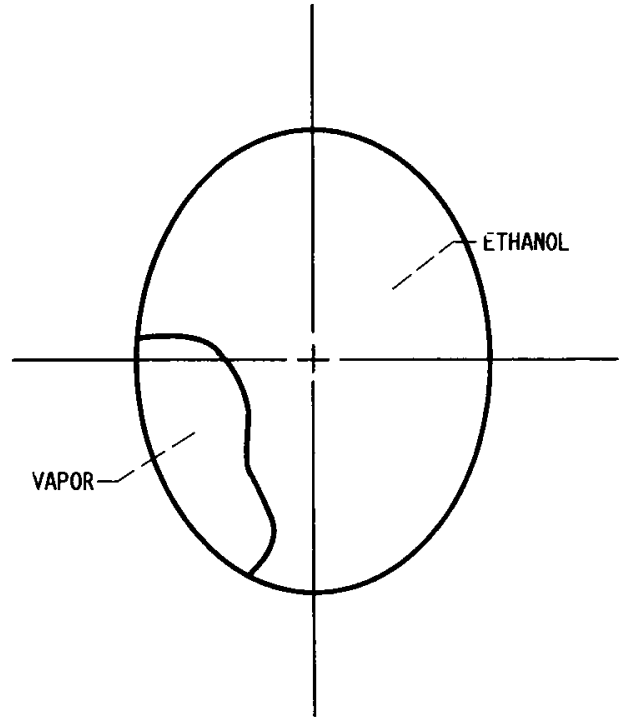

(B) QUALITATIVE VIEW OF LIQUID-VAPOR INTERFACE: TIME, $0.15 \mathrm{SEC}$.

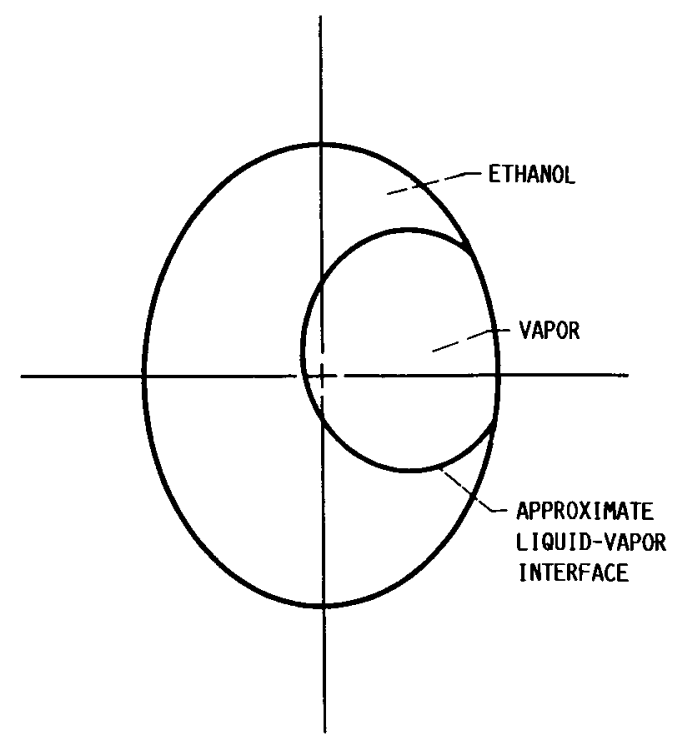

(D) QUALITATIVE VIEW OF LIQUID-VAPOR INTERFACE; TIME, 1.72 SEC.

FIgURE 13. - PLOTS OF LIQUID-VAPOR INTERFACE CONI JURATION - TEST 3. FILL LEVEL, 90 PERCENT: IMPULSE, $0.10 \mathrm{~g}$ FOR $0.160 \mathrm{SEC}$. (TIME MEASURED FROM START OF IMPULSIVE ACCELERATION.) 


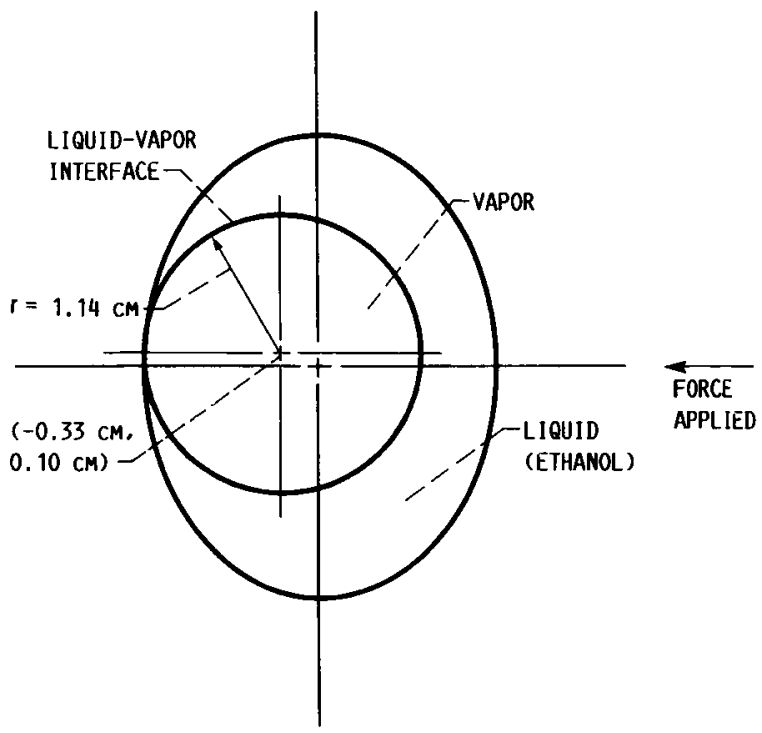

(A) EQUILIBRIUM ZERO-GRAVITY CONFIGURATION.

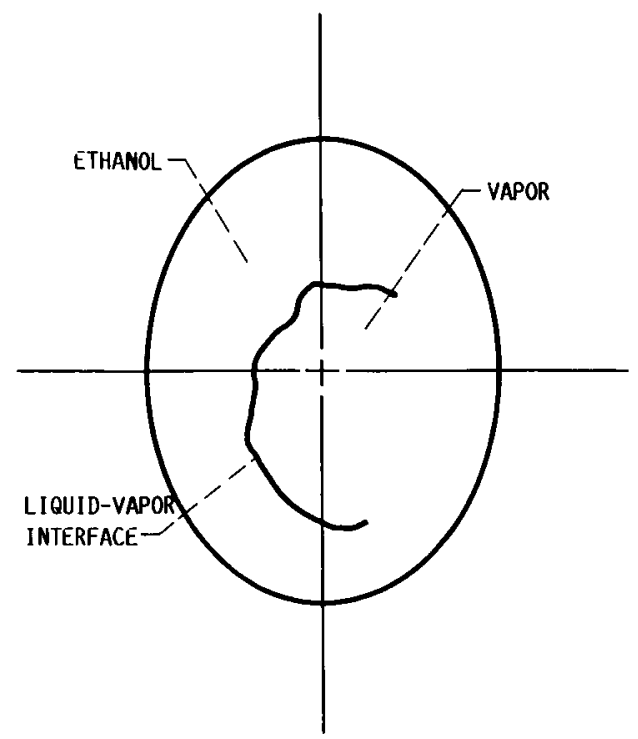

(C) QUANTITATIVE VIEW OF LIQUID-VAPOR INTERFACE: TIME, 0.67 SEC.

FIGURE 14. - PLOTS OF LIQUID-VAPOR INTERFACE CONFIGURATIONS - TEST 4. FILL LEVEL. 75 PERCENT; IMPULSE. $0.22 \mathrm{~g}$ FOR 0.109 SEC. (TIME MEASURED FROM START OF IMPULSIVE ACCELERATION.)

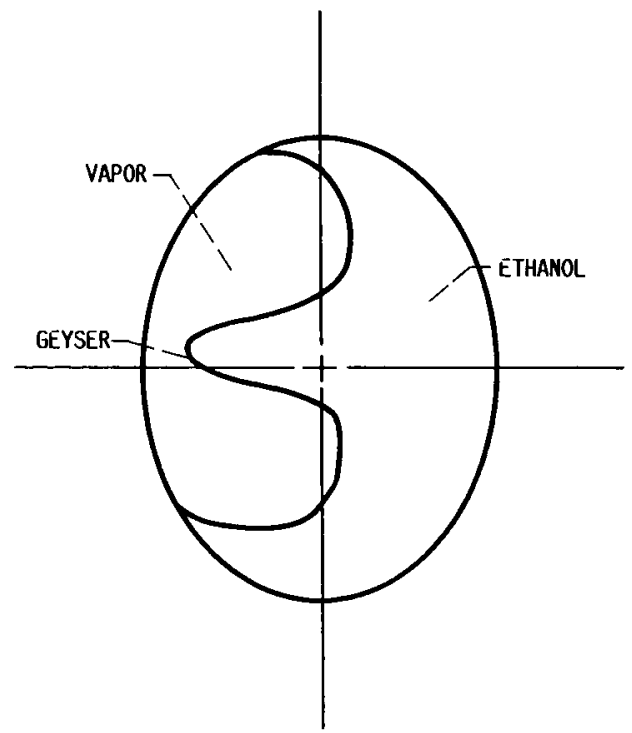

(B) QUALITATIVE VIEW OF LIQUID-VAPOR INTERFACE: TIME, $0.10 \mathrm{sEC}$.

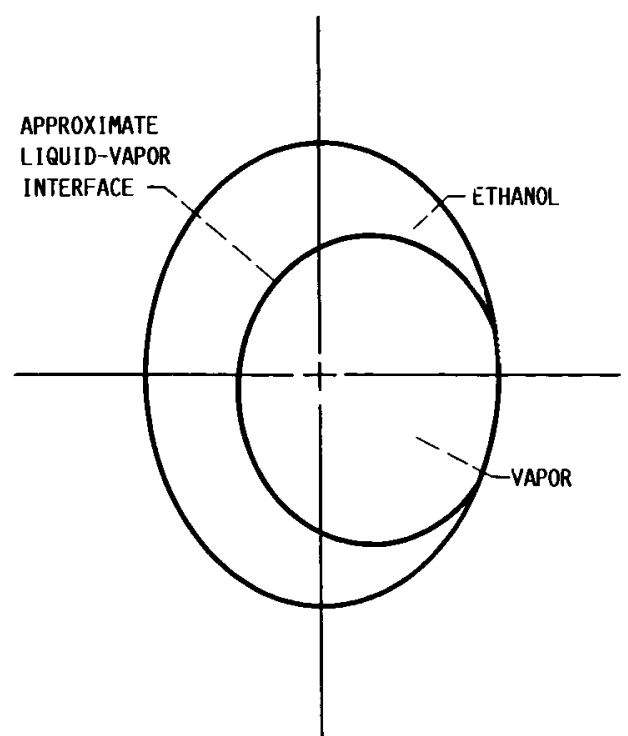

(D) QUALITATIVE VIEW OF LIQUID-VAPOR INTERFACE

TINE. $1.18 \mathrm{SEC}$. 


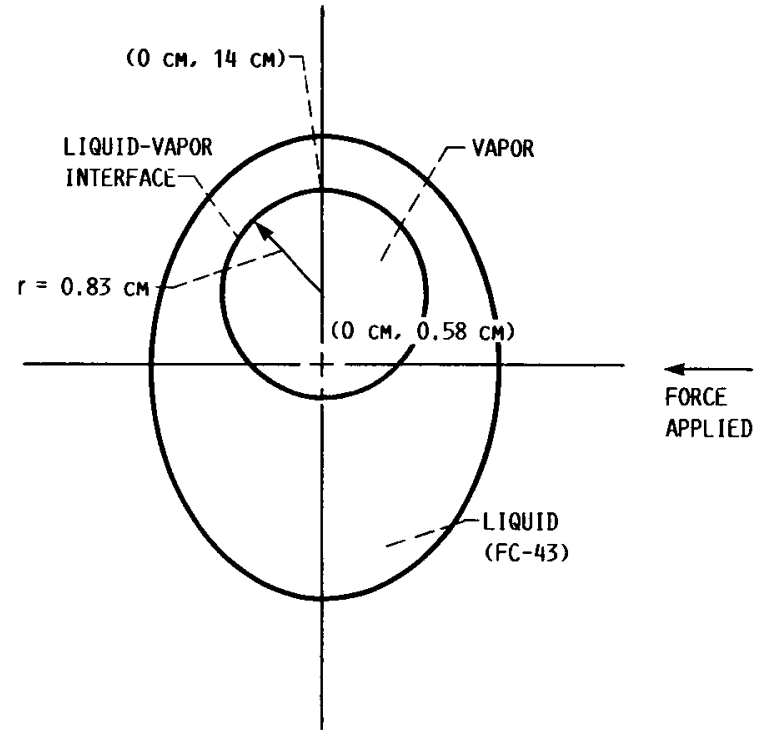

(A) EQUILIBRIUM ZERO-GRAVITY CONFIGURATION.

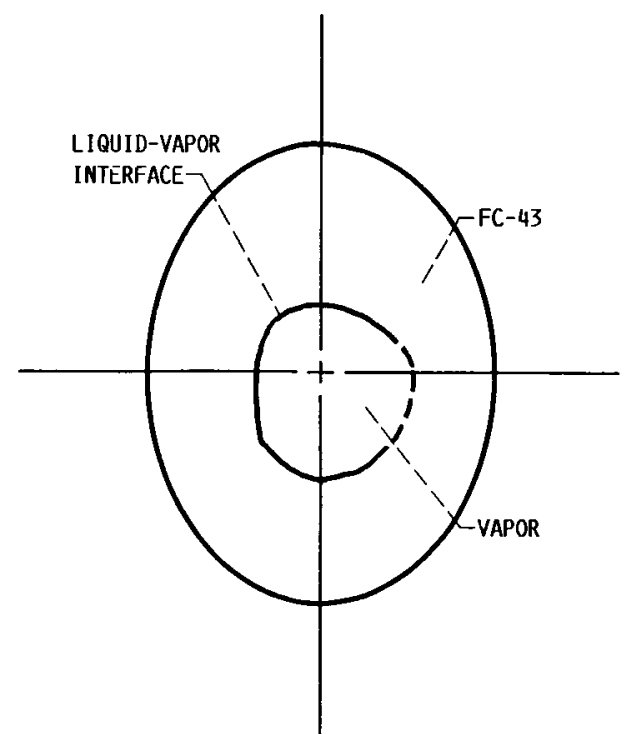

(C) QUANTITATIVE VIEW OF LIQUID-VAPOR INTERFACE; TIME, 0.84 SEC.

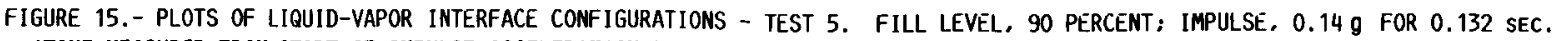
(TIME MEASURED FROM START OF IMPULSE ACCELERATION.)

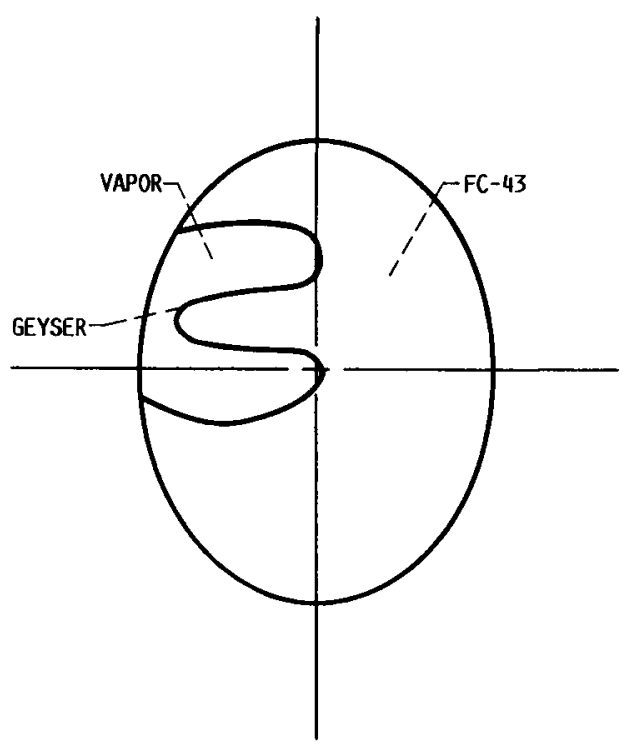

(B) QUALITATIVE VIEW OF LIQUID-VAPOR INTERFACE; TIME, 0.13 SEC.

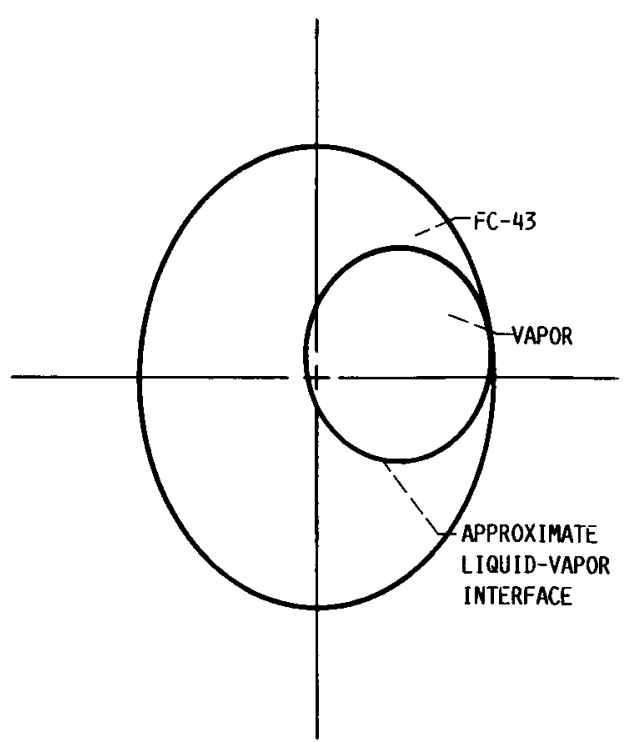

(D) QUALITATIVE VIEW OF LIQUID-VAPOR INTERFACE: TIME. $1.55 \mathrm{SEC}$ 


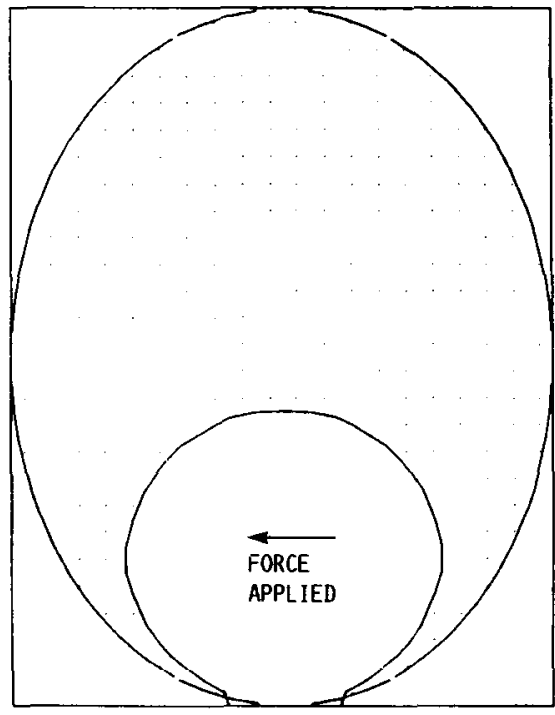

(A) LIQUID-VAPOR INTERFACE CONFIGURATION BEFORE START OF IMPULSIVE ACCELERATION.

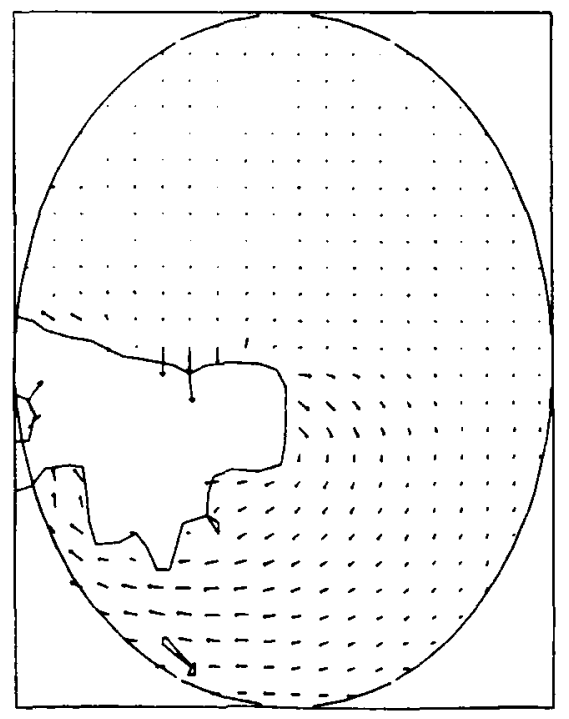

(D) INTERFACE CONFIGURATION AND LIQUID VELOCITY VECTORS 0.25 SEC AFTER IMPULSE INITIATION (MAXIMUM VELOCITY $\approx 10 \mathrm{cM} / \mathrm{SEC}$ ).

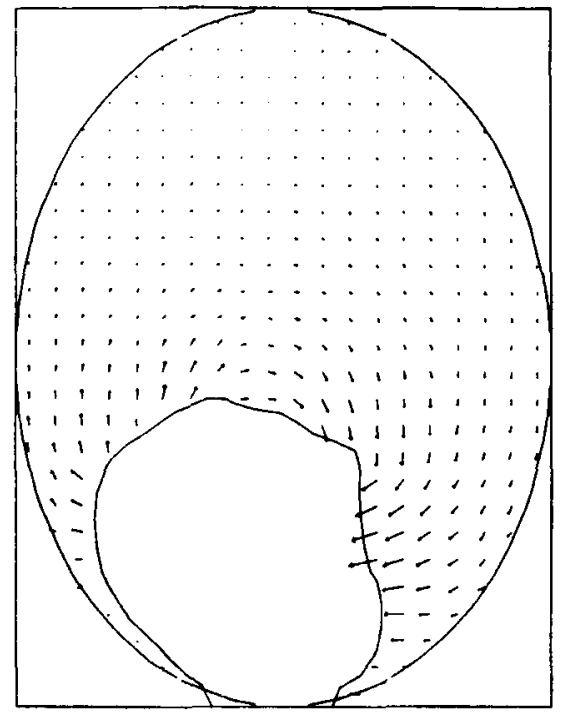

(B) INTERFACE CONFIGURATION AND LIQUID VELOCITY VECTORS 0.05 SEC AFTER IMPULSE INITIATION (MAXIMUM VELOCITY $\approx 15 \mathrm{cM} / \mathrm{SEC}$ ).

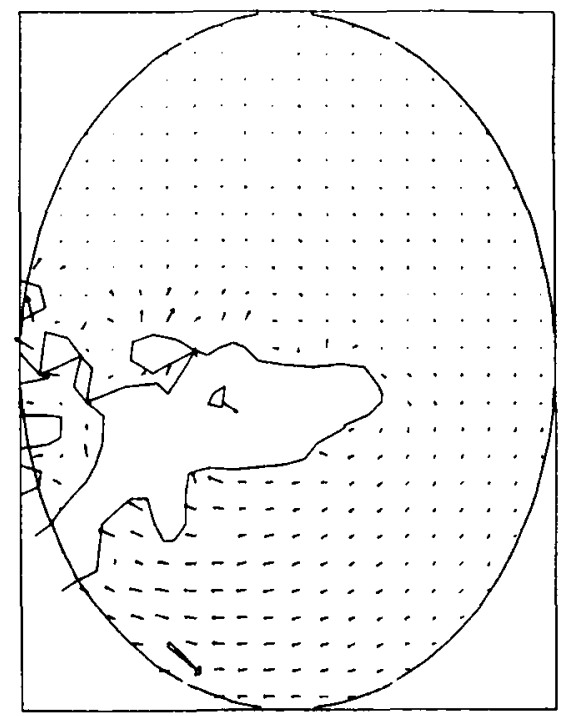

(E) INTERFACE CONFIGURATION AND LIQUID VELOCITY VECTORS 0.35 SEC AFTER IMPULSE INITIATION (MAXIMUM VELOCITY $\approx 7 \mathrm{cM} / \mathrm{SEC}$ ).

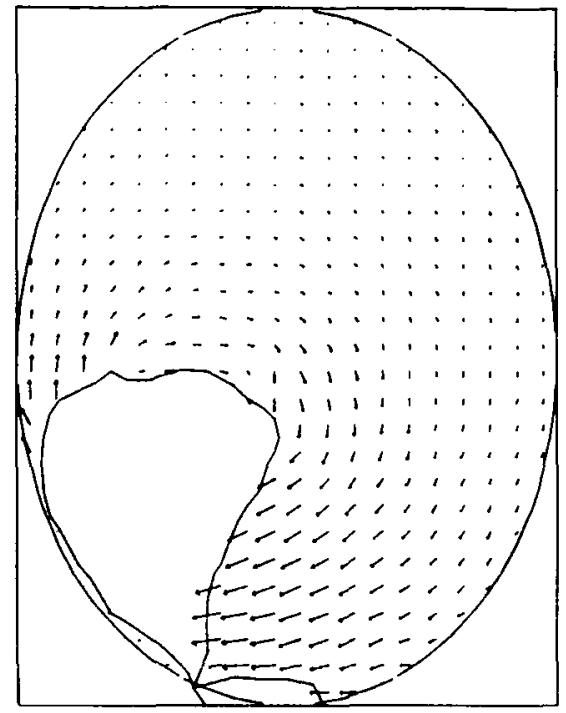

(C) INTERFACE CONFIGURATION AND LIQUID VELOCITY VECTORS 0.10 SEC AFTER IMPULSE INITIATION (MAXIMUM VELOCITY $\approx 27 \mathrm{cM} / \mathrm{SEC}$ ).

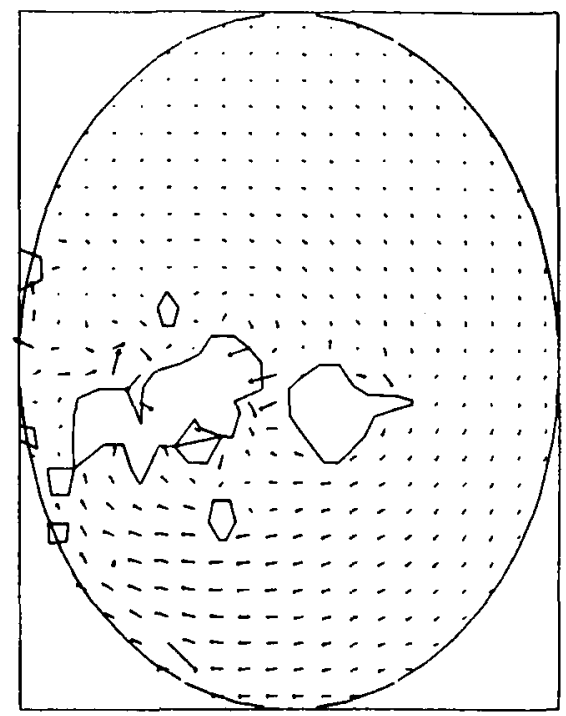

(F) INTERFACE CONFIGURATION AND LIQUID VELOCITY VECTORS 0.60 SEC AFTER IMPULSE INITIATION (MAXIMUM VELOCITY $\approx 5 \mathrm{~cm} / \mathrm{SEC}$ ).

FIGURE 16. - NUMERICAL MODELING OF LIQUID AND VAPOR MOTION IN RESPONSE TO IMPULSIVE ACCELERATION - TEST 1. FILL LEVEL, 90 PERCENT: IMPULSE, $0.25 \mathrm{~g}$ FOR $0.101 \mathrm{sEC}$. 


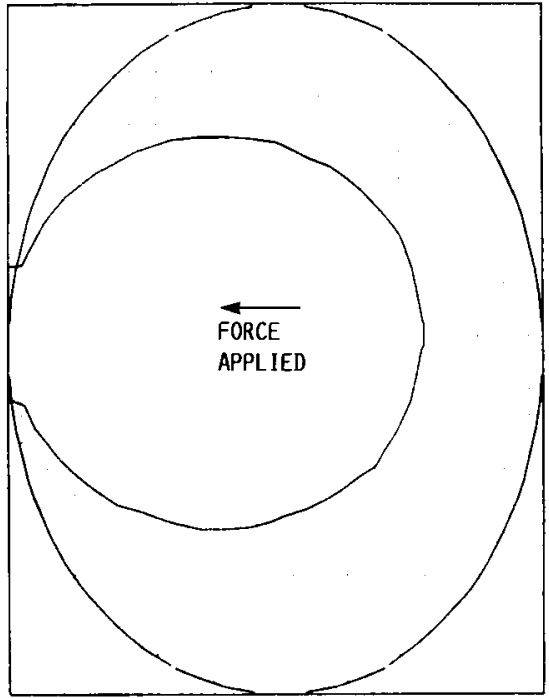

(A) LIQUID-VAPOR INTERFACE CONFIGURATION BEFORE START OF IMPULSIVE ACCELERATION.

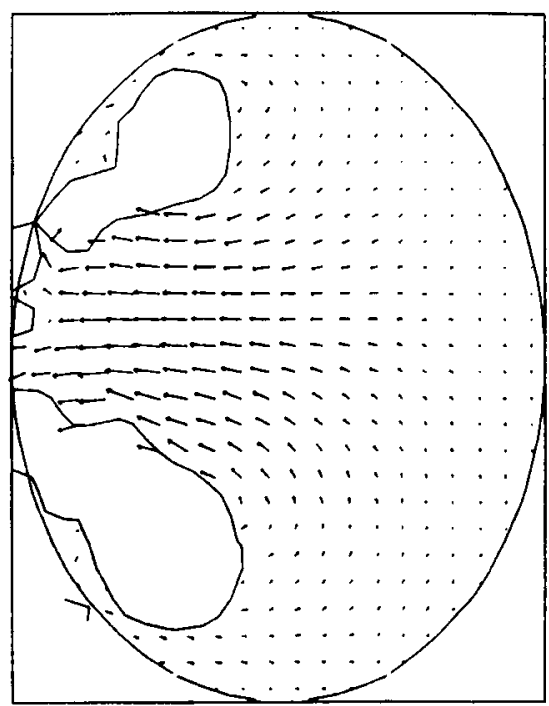

(D) INTERFACE CONFIGURATION AND LIQUID VELOCITY VECTORS 0.15 SEC AFTER IMPULSE INITIATION (MAXIMUM VELOCITY $\approx 14 \mathrm{cM} / \mathrm{SEC}$ ).

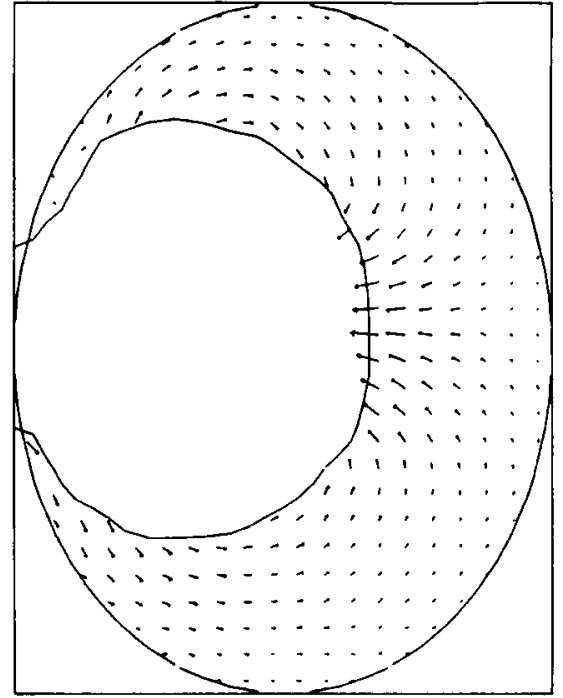

(B) INTERFACE CONFIGURATION AND LIQUID VELOCITY VECTORS 0.05 SEC AFTER IMPULSE INITIATION (MAXIMUM VELOCITY $\approx 16 \mathrm{cM} / \mathrm{SEC}$ ).

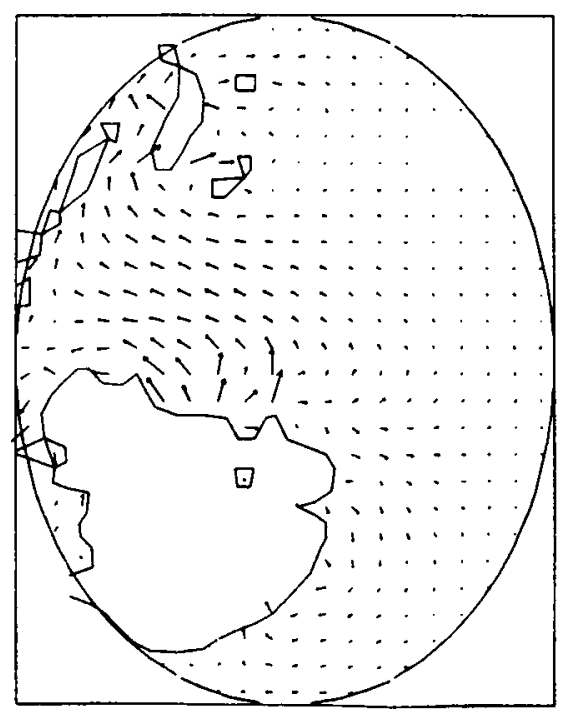

(E) INTERFACE CONFIGURATION AND LIQUID VELOCITY VECTORS 0.35 SEC AFTER IMPULSE INITIATION (MAXIMUM VELOCITY $\approx 5 \mathrm{cM} / \mathrm{SEC}$ ).

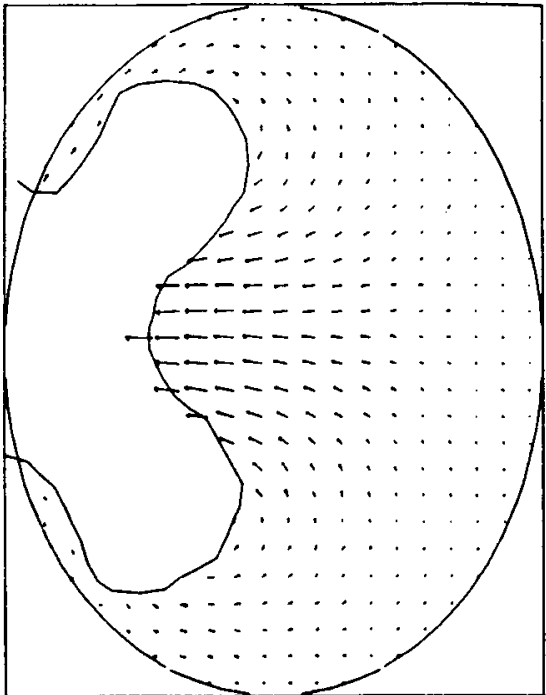

(C) INTERFACE CONFIGURATION AND LIQUID VELOCITY VECTORS 0.10 SEC AFTER IMPULSE INITIATION (MAXIMUM VELOCITY $\approx 27 \mathrm{cM} / \mathrm{SEC}$ ).

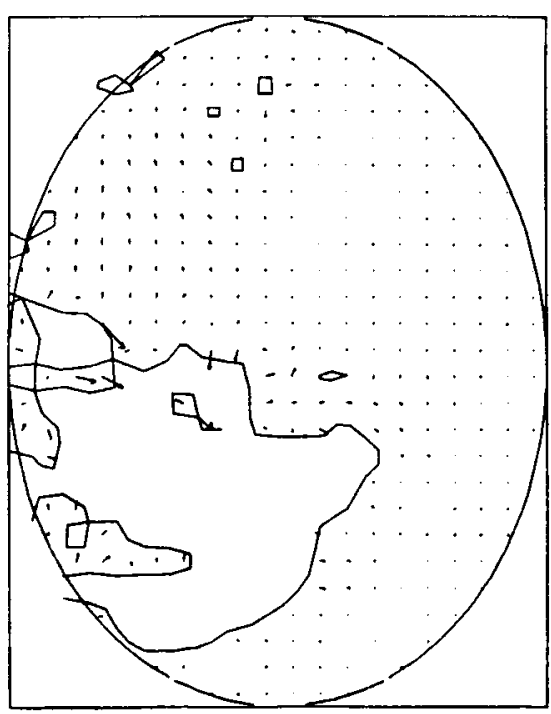

(F) INTERFACE CONFIGURATION 0.65 SEC AFTER IMPULSE INITIATION. BULLK LIQUID VELOCITY VECTORS NEARLY ZERO.

FIGURE 17. - NUMERICAL MODEL ING OF LIQUID AND VAPOR MOTION IN RESPONSE TO IMPULSIVE ACCELERATION - TEST 4. FILL LEVEL, 75 PERCENT; IMPULSE, $0.22 \mathrm{~g}$ FOR $0.104 \mathrm{SEC}$. 


\section{ORIGINAL PAGE IS OF POOR QUALTY}

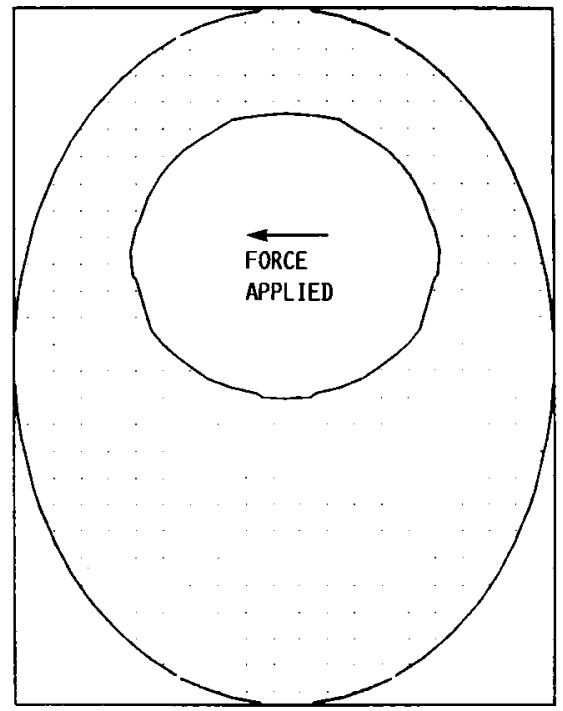

(A) LIQUID-VAPOR INTERFACE COMFIGURATION BEFORE START OF IMPULSIVE ACCELERATION.

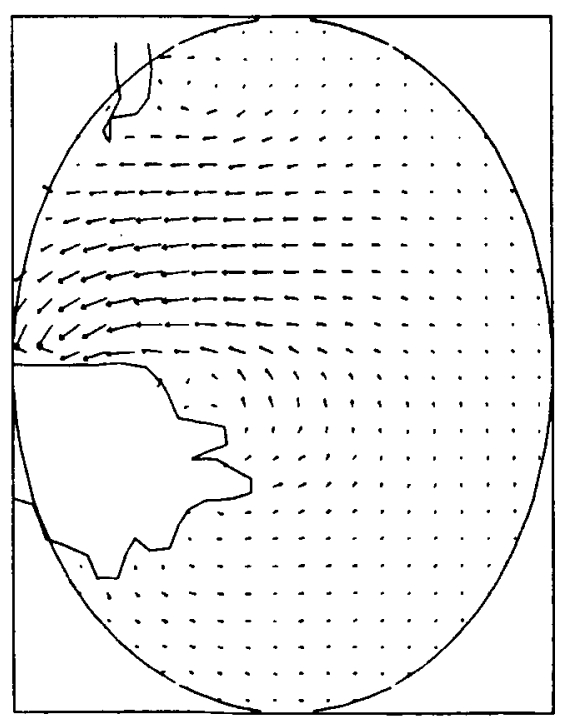

(D) INTERFACE CONFIGURATION AND LIQUID VELOCITY VECTORS 0.25 SEC AFTER IMPULSE INITIATION (MAXIMUM VELOCITY $\approx 7 \mathrm{~cm} / \mathrm{SEC}$ ).

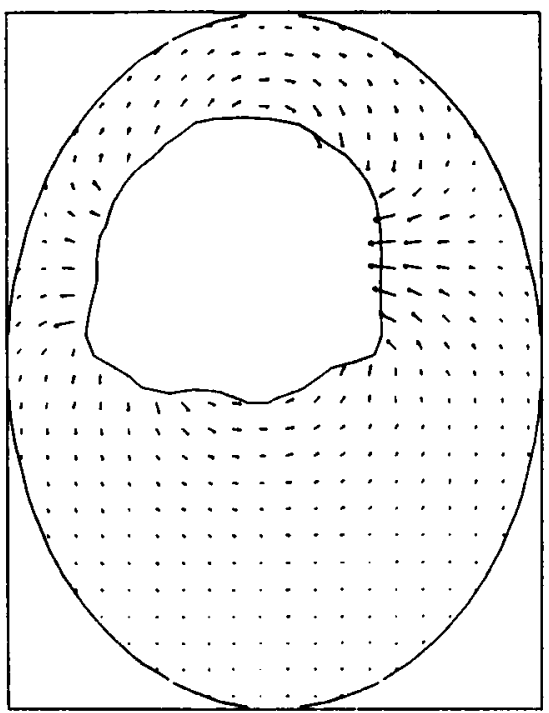

(B) INTERFACE CONFIGURATION AND LIQUID VELOCITY VECTORS 0.05 SEC AFTER IMPULSE INITIATION (MAXIMUM VELOCITY $\approx 10 \mathrm{~cm} / \mathrm{SEC}$ ).

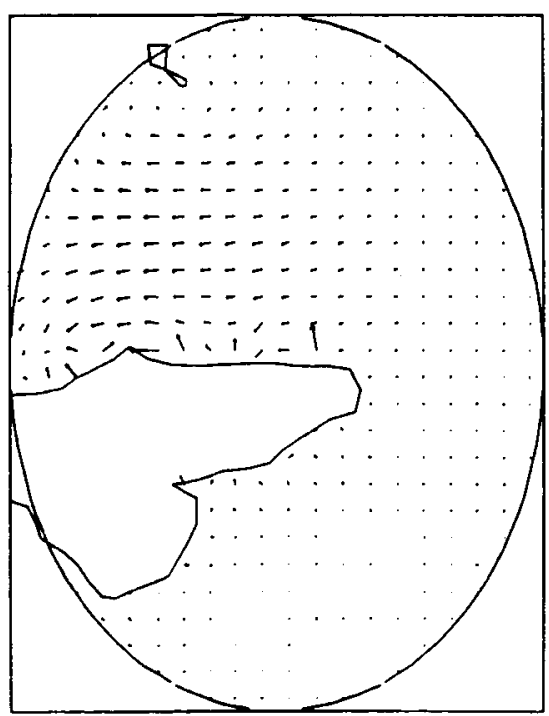

(E) INTERFACE CONFIGURATION AND LIQUID VELOCITY VECTORS 0.45 SEC AFTER IMPULSE INITIATION (MAXIMUM VELOCITY $\approx 6 \mathrm{~cm} / \mathrm{SEC}$ ).

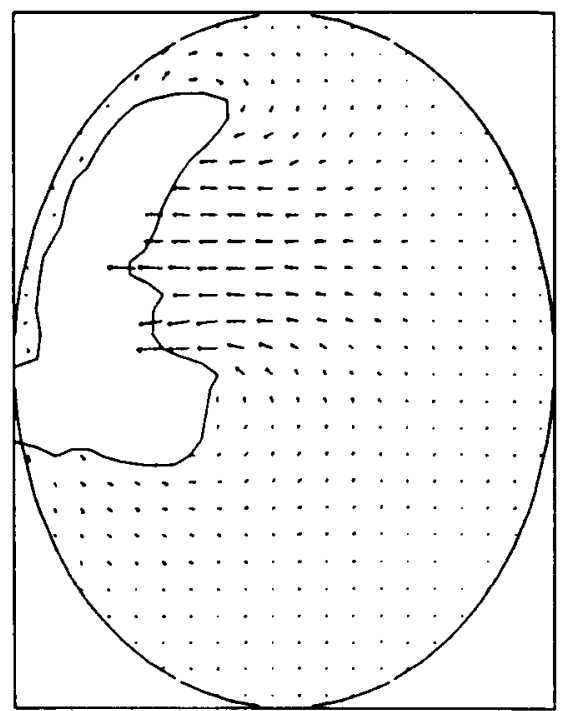

(C) INTERFACE CONFIGURATION AND LIQUID VELOCITY VECTORS 0.13 SEC AFTER IMPULSE INITIATION (MAXIMUM VELOCITY $\approx 22 \mathrm{cM} / \mathrm{SEC}$ ).

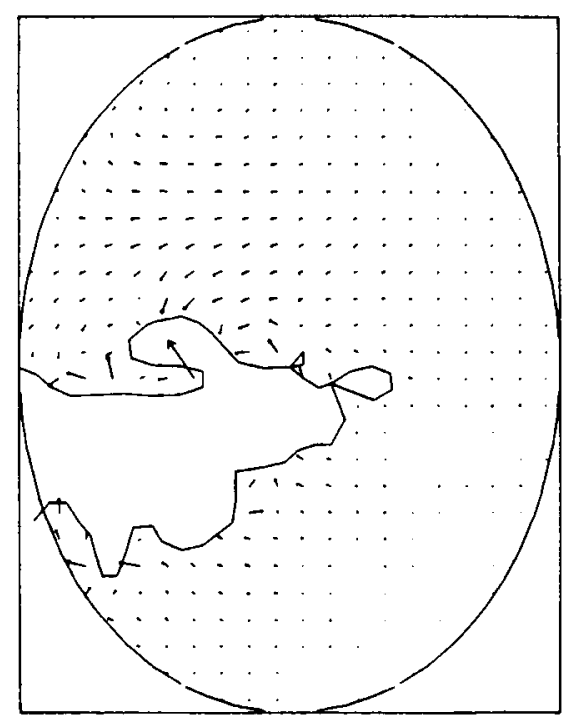

(F) INTERFACE CONFIGURATION AND LIQUID VELOCITY VECTORS 0.85 SEC AFTER IMPULSE INITIATION (MAXIMUM VELOCITY $\approx 4 \mathrm{cM} / \mathrm{SEC}$ ).

FIGURE 18. - NUMERICAL MODELING OF LIQUID AND VAPOR MOTION IN RESPONSE TO IMPULSIVE ACCELERATION - TEST 5. FILL LEVEL, 90 PERCENT: IMPULSE, $0.14 \mathrm{~g}$ FOR $0.132 \mathrm{sEC}$. 


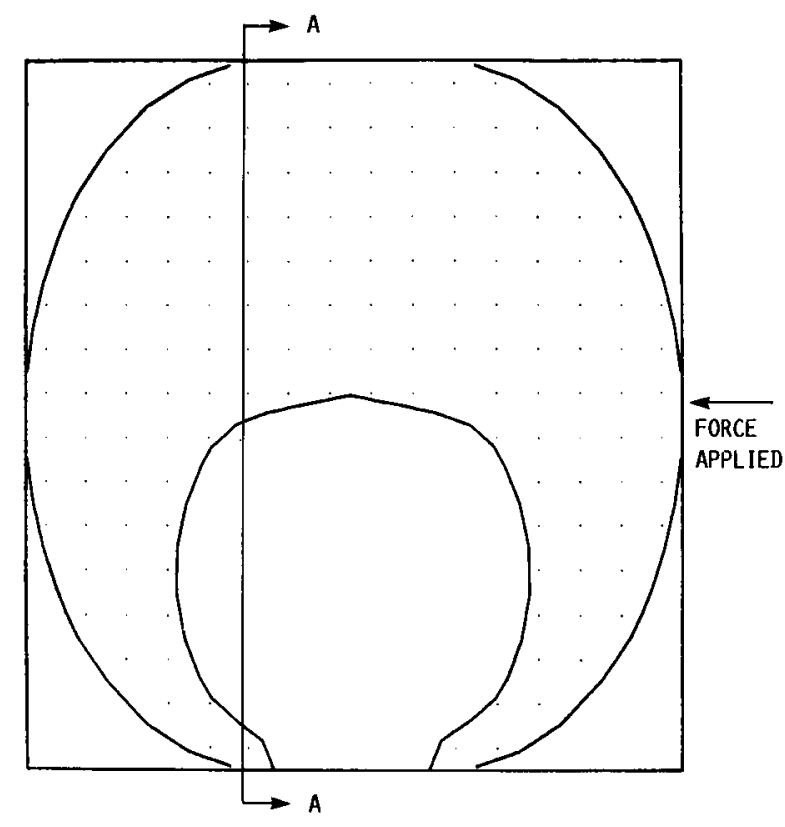

(A) CROSS-SECTIONAL VIEW OF LIQUID-OXYGEN TANK.

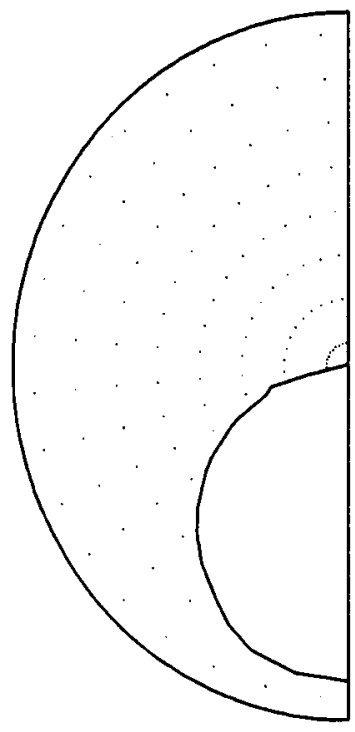

(B) SECTION A-A.

FIGURE 19. - NUMERICAL MODELING OF CENTAUR LIQUID-OXYGEN PROPELLANT MOTION DURING SEPARATION MANEUVER. INITIAL ASSUMED WORST-CASE LIQUID-VAPOR INTERFACE CONFIGURATION; FILL LEVEL, 89 PERCENT, IMPULSE APPLIED FOR 0.44 SEC WITH MAXIMUM ACCELERATION OF $0.133 \mathrm{~g}$.
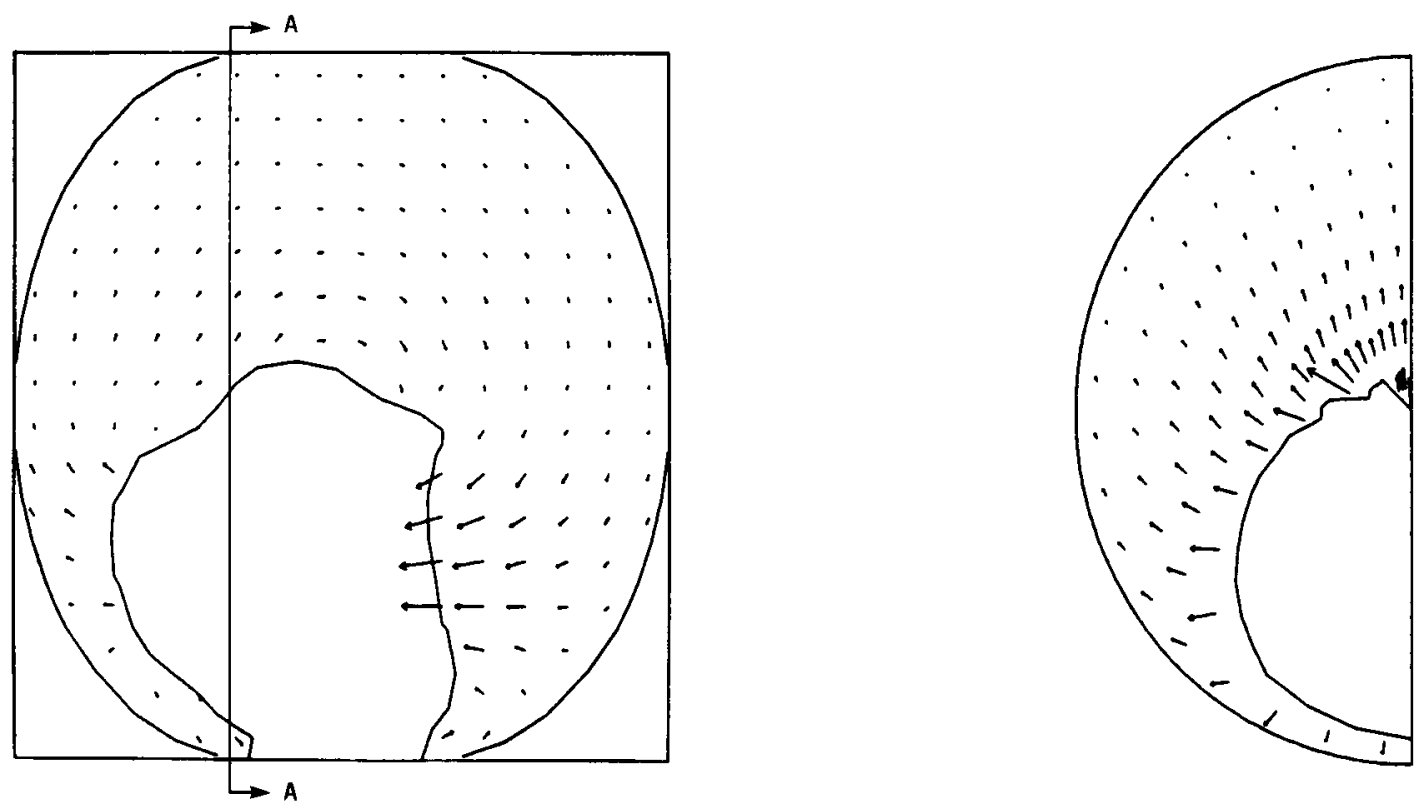

(A) CROSS-SECTIONAL VIEW OF LIQUID-OXYGEN TANK.

(B) SECTION A-A.

FIGURE 20. - NUMERICAL MODELING OF CENTAUR LIQUID-OXYGEN PROPELLANT MOTION DURING SEPARATION MANEUVER. TIME, 1.0 SEC AFTER IMPULSE INITIATION; MAXIMUM VELOCITY $\approx 50 \mathrm{~cm} / \mathrm{sEC}$. 

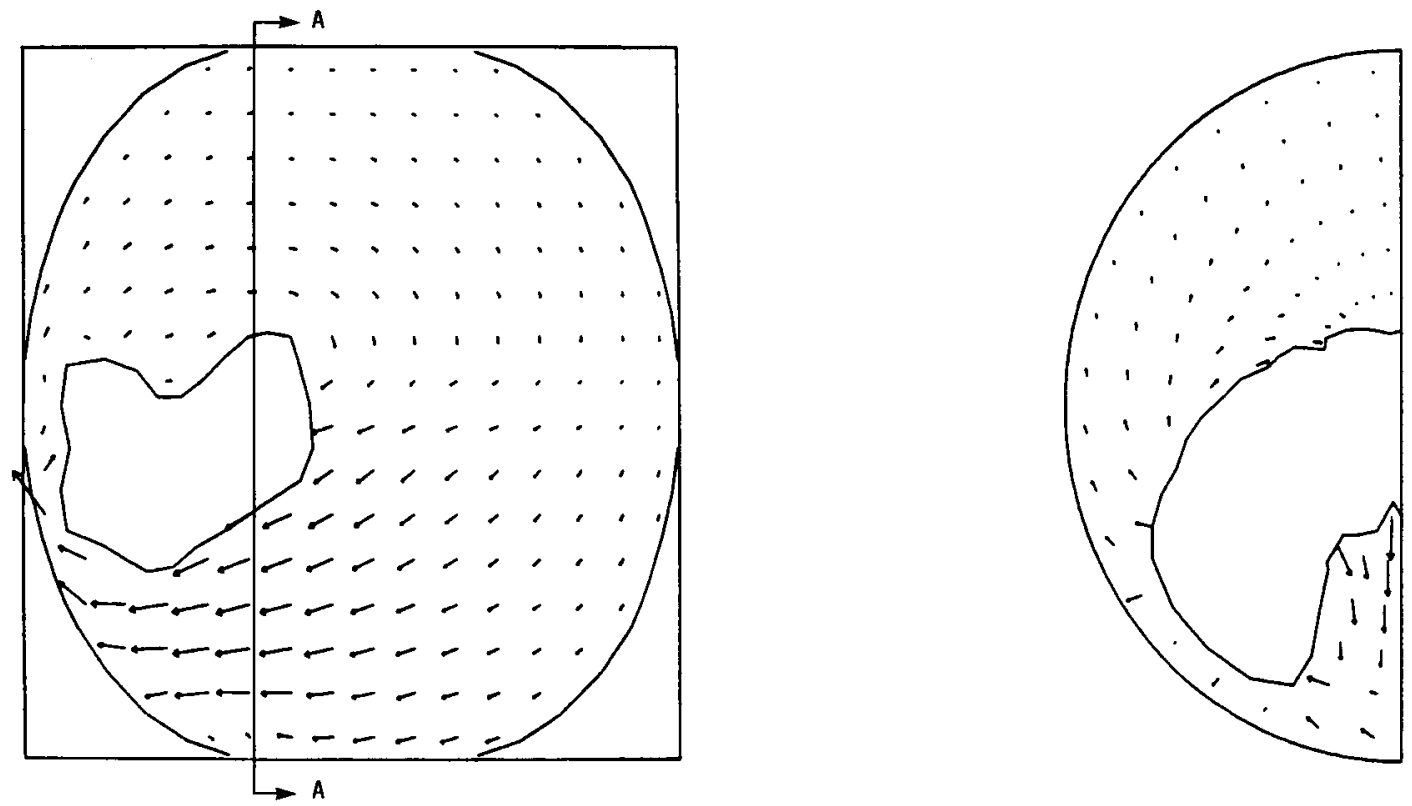

(A) CROSS-SECTIONAL VIEW OF LIQUID-OXYGEN TANK.

(B) SECTION A-A.

FIGURE 21. - NUMERICAL MODELING OF CENTAUR LIQUID-OXYGEN PROPELLANT MOTION DURING SEPARATION MANEUVER. TIME, 10 SEC AFTER IMPULSE INITIATION: MAXIUMUM VELOCITY $\approx 12 \mathrm{cM} / \mathrm{sEC}$.

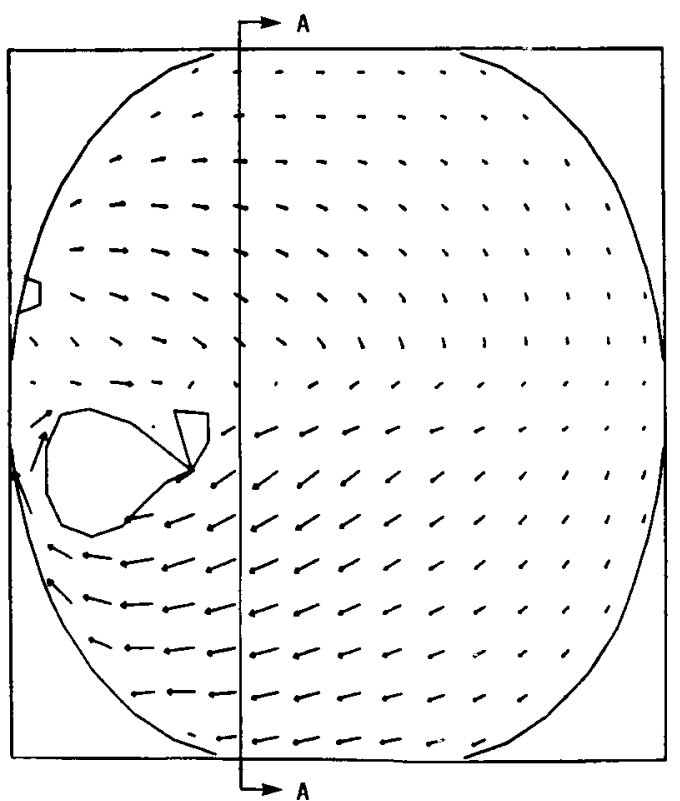

(A) CROSS-SECTIONAL VIEW OF LIQUID-OXYGEN TANK.

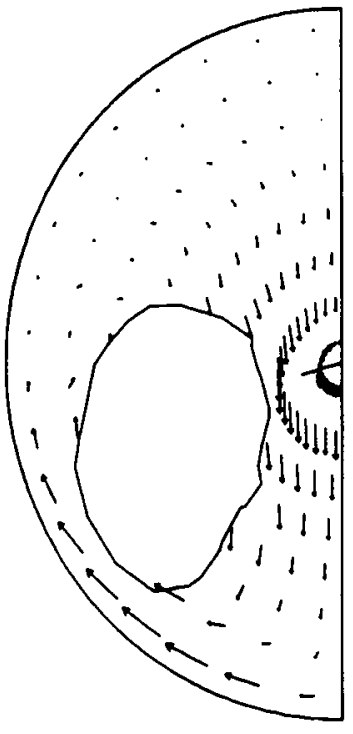

(B) SECTION A-A.

FiguRE 22. - NUMERICAL MODELING OF CENTAUR LIQUID-OXYGEN PROPELlaNt MOTION DURING SEPARATION MANEUVER. TIME, 20 SEC AFTER IMPULSE INITIATION; MAXIMUM VELOCITY $\approx 12 \mathrm{cM} / \mathrm{SEC}$. 


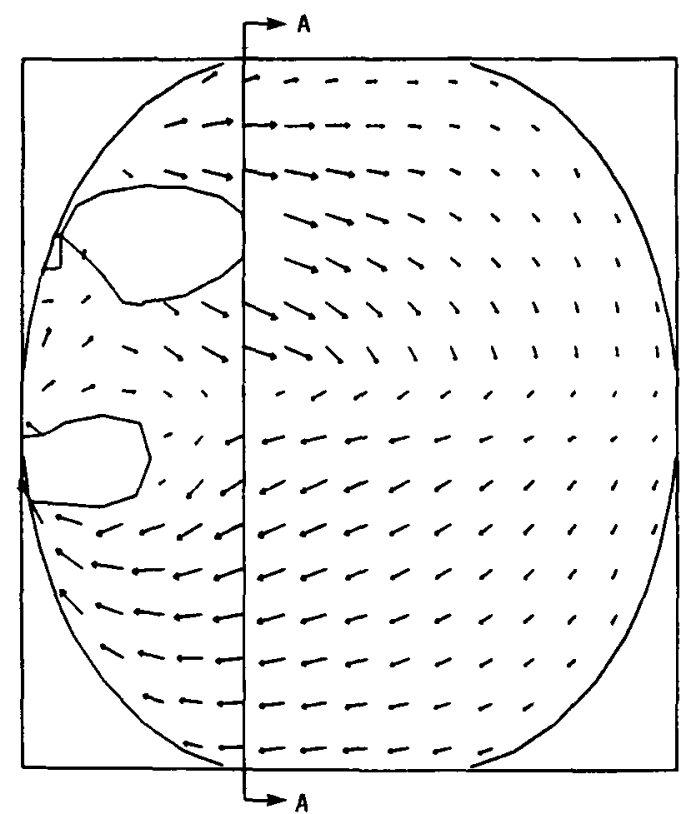

(A) CROSS-SECTIONAL VIEW OF LIQUID-OXYGEN TANK.

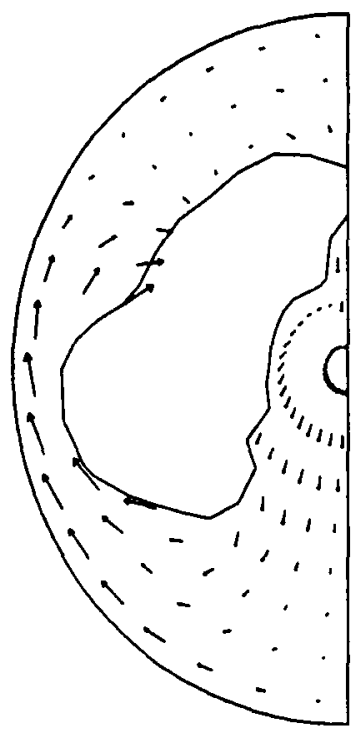

(B) SECTION A-A.

FiguRE 23. - NUMERICAL MODELING OF CENTAUR LIQUid-OXYGEN PROPELLANT MOTION DURING SEPARATION MANEUVER. TIME, 40 SEC AFTER IMPULSE INITIATION: MAXIMUM VELOCITY $\approx 7 \mathrm{cM} / \mathrm{SEC}$. 


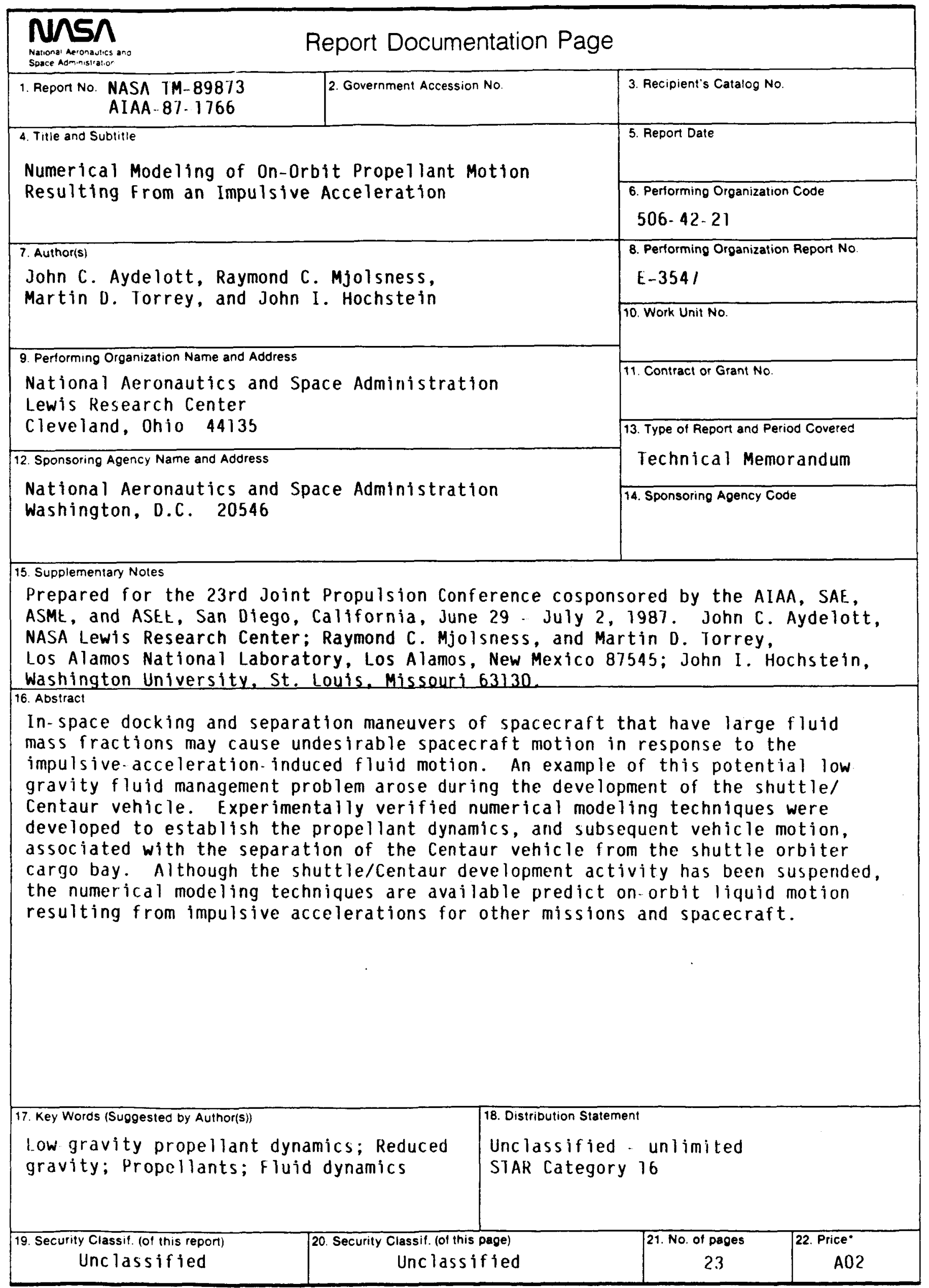

